\title{
Guideline on the management of psoriasis in South Africa
}

\author{
N Raboobee (Chair of Working Group), J Aboobaker, H F Jordaan, W Sinclair, J M Smith, G Todd, R Weiss, D Whitaker, Working \\ Group of the Dermatological Society of South Africa
}

\begin{abstract}
Background. Psoriasis vulgaris is a chronic, relapsing, immunemediated, potentially devastating disease, influenced by genetic and environmental factors, that can cause substantial morbidity and psychological stress and have a profound negative impact on patient quality of life.

Objective. These guidelines for the management of psoriasis have been developed in an attempt to improve the outcomes of treatment of this condition in South Africa. Psoriasis has a major impact on the quality of life of sufferers, and it is expected that these guidelines, if implemented, will play a role in achieving improved outcome.

Scope. These guidelines were developed to address the diagnosis and treatment of psoriasis, of differing degrees of severity and in patients of all ages, by all health care professionals involved with its management.

Recommendations. All health care workers involved in the management of psoriasis should take note of these guidelines and try to implement them in clinical practice as far as possible. All treatment methods and procedures not substantiated by evidence from the literature should be discontinued and avoided to decrease the financial burden of psoriasis treatment.
\end{abstract}

Validation. These guidelines were developed through general consensus by a group of 8 South African dermatologists (the 'Working Group') sanctioned by the Dermatological Society of South Africa (DSSA), by adaptation for the South African situation of the current guidelines used in the USA, the UK, Germany, Canada and Finland. Draft documents were made available for comment to the dermatological community as a whole via the official website of the DSSA, and the guidelines were presented and discussed at the annual congress of the DSSA in 2008. All input from these sources, where appropriate, were then incorporated into these guidelines. Guidelines sponsor. Schering-Plough initiated the project and sponsored the meetings of the working group and all costs generated by these meetings.

Plans for guideline revision. The field of biologicals and cytokine modulators is in a rapid phase of development, and revision of the scope and content of these guidelines will be ongoing as longer-term data emerge.

S Afr Med J 2010; 100: 255-282

\section{Limitations of the guidelines}

These guidelines have been prepared for dermatologists and other health care professionals on behalf of the Working Group of the Dermatological Society of South Africa and reflect the best data available at the time the report was prepared. Caution should be exercised in interpreting the data; the results of future studies may require alteration of the conclusions or recommendations in this report. It may be necessary or even desirable to depart from the guidelines in the interests of specific patients and special circumstances. These guidelines do not represent all the possible methods of management applicable to all patients, do not exclude any other reasonable methods, and will not ensure successful treatment in every situation. The unique circumstances of each patient should be taken into account by the responsible physician making decisions on any specific therapy.

Just as adherence to guidelines may not constitute defence against a claim of negligence, so deviation from them should not necessarily be deemed negligent.

\section{Introduction and methods}

Psoriasis vulgaris is a chronic, relapsing, immune-mediated, potentially devastating disease, influenced by genetic and environmental factors, that can cause substantial morbidity and psychological stress and have a profound negative impact on patient quality of life. ${ }^{1,2}$

\subsection{Incidence/prevalence}

Approximately $2 \%$ of people worldwide have psoriasis, onethird of whom have a moderate to severe form of the disease. ${ }^{3}$ Age at onset is usually $16-22$ years ('early') or $57-60$ years ('late'). ${ }^{4}$ The genetic background of these two types differs. ${ }^{5}$ Males and females are affected in equal numbers. ${ }^{6}$

\subsection{Genetic factors}

Genetic predisposition to psoriasis follows a multifactorial pattern. Approximately 10 susceptibility genes (loci) have been identified. The most significant locus (PSORS1) lies within chromosome $6 \mathrm{p} 21.3 .^{7}$ Only about $10 \%$ of susceptibility gene carriers will develop the disease (low penetrance). ${ }^{5,8}$

\subsection{Pathophysiology}

Psoriasis is characterised by an abnormal regulation of the interaction between $\mathrm{T}$ cells and keratinocytes. The T-cell cytokine secretion profile resembles that of a Th-1 response. ${ }^{9}$

\subsection{Environmental factors and triggers (Table I)}

External factors (infections, streptococcal in particular, skin injuries, certain drugs) often trigger the onset of psoriasis. ${ }^{9}$ Stress, smoking and excessive alcohol consumption may also be connected with the onset or worsening of the disease. ${ }^{9}$ 
Table I. Factors that trigger, precipitate or worsen psoriasis

\begin{tabular}{|c|c|c|}
\hline External factors & Lifestyle factors & Medications \\
\hline Infections (esp. streptococcal) & Stress & Lithium \\
\hline \multirow[t]{3}{*}{ Skin injuries } & Smoking & Chloroquine \\
\hline & Excessive alcohol consumption & Beta-adrenoreceptor blockers \\
\hline & & ACE inhibitors \\
\hline
\end{tabular}

Drugs thought to precipitate or worsen psoriasis include alcohol, lithium, chloroquine, beta-adrenoreceptor blocking drugs, angiotensin-converting enzyme (ACE) inhibitors and non-steroidal anti-inflammatories (NSAIDs). ${ }^{9}$

\section{Diagnosis}

Although a biopsy may be required in atypical cases, ${ }^{10}$ the diagnosis of psoriasis is usually made clinically, without difficulty, based on the characteristic features. ${ }^{11}$

\subsubsection{Skin}

Characteristic cutaneous lesions facilitate diagnosis.

- The most common lesions are plaques that are sharply demarcated, slightly elevated and covered with silvery scales.

- Gentle scraping of the scales reveals minute capillary bleeding points (Auspitz sign).

- The elbows, knees, legs, lower back, scalp, and glans penis are the sites most often affected.

\subsubsection{Nails}

Nail involvement is common and can present as:

- pitting

- separation of the distal nail plate from the nail bed (onycholysis)

- pinkish-brown flecks beneath the nail plate ('oil spots')

- subungual hyperkeratosis.

Acrodermatitis continua of Hallopeau is a painful, localised, pustular form of psoriasis which often leads to nail deformity.

\subsubsection{Joints}

Psoriasis may also affect the joints in 5 - 10\% of cases.

\subsection{Common types of psoriasis (Table II)}

- Plaque psoriasis accounts for $80-90 \%$ of cases. ${ }^{12}$ It is a stationary form of the disease with the lesions often covered with thick, silvery or waxy scales. Patients may have involvement ranging from only a few plaques to numerous lesions covering almost the entire body surface. ${ }^{13}$

- Guttate psoriasis is often triggered by tonsillitis. Its small lesions are widely distributed over the body.

- Flexural (inverse) psoriasis is localised to the main skin folds (genitocrural area, navel, axillae, submammary region).

- Pustular psoriasis may be generalised or localised to the palms and soles.

\subsection{Clinical features}

Table II. Common types of cutaneous psoriasis and their distribution

\begin{tabular}{ll}
\hline Type & Distribution/description \\
\hline Plaque psoriasis & $\begin{array}{l}\text { Stationary form of the disease } \\
\text { Thick, silvery or waxy scales } \\
\text { Localised or generalised } \\
\text { Small 'teardrop' lesions, wide } \\
\text { distribution over the body } \\
\text { Main skinfolds (genitocrural area, } \\
\text { navel, axillae, submammary } \\
\text { region). }\end{array}$ \\
Pustular psoriasis & $\begin{array}{l}\text { Generalised or localised to the } \\
\text { palms and soles } \\
\text { Generalised }\end{array}$ \\
\hline $\begin{array}{l}\text { Erythrodermic psoriasis } \\
\text { (refractory to treatment) }\end{array}$ & \\
\hline
\end{tabular}

- Erythrodermic psoriasis is a generalised form of the disease and is most refractory to treatment.

\subsection{Differential diagnosis (Table III)}

\subsubsection{Scalp}

- Seborrhoeic dermatitis. The flakes are thinner and 'greasier', and the condition responds better to treatment. It is often difficult to differentiate seborrhoeic dermatitis from psoriasis unless other skin areas offer additional information.

- Fungal infection of the scalp mostly affects children. This diagnosis can be excluded by microscopy and a negative culture for fungi.

- Neurodermatitis of the neck (lichen simplex nuchae) is characterised by an isolated, lichenified, pruritic plaque covered with thin scales.

\subsubsection{Flexures}

- Seborrhoeic dermatitis may resemble flexural psoriasis. Other skin areas should be examined.

\section{Table III. Differential diagnosis of psoriasis}

Scalp
Seborrhoeic dermatitis
Fungal infection
Neurodermatitis
Flexures
Seborrhoeic dermatitis
Fungal infection
Candidiasis
Erythrasma
Hands and feet
Hyperkeratotic eczema
Fungal infection


- Fungal infection (tineas) may resemble psoriasis; however, it usually heals in the centre and expands peripherally. Microscopy and fungal culture are diagnostic.

- Candidiasis is not often seen in young and middle-aged patients. It presents as a moist area of erythema and maceration with outlying 'satellite lesions'.

- Erythrasma is a macular brown area with few symptoms, most often found in the axillae or groin. It is caused by an overgrowth of diphtheroids, which are part of the normal skin flora. These areas fluoresce coral-pink under Wood's light.

\subsubsection{Hands, feet}

- Hyperkeratotic eczema of the palms and palmoplantar pustulosis may be difficult to differentiate from psoriasis. The entire skin should be examined.

- Fungal infection can easily be diagnosed by microscopic examination and culture.

\section{Classification}

Classification of psoriasis is based on the type of psoriasis (see above) and on disease severity, which is described as mild, moderate or severe.

Severity is a qualitative decision, hinging on the measures of disease activity, resistance to prior therapy and psychosocial considerations. Various measures of severity exist and are listed in Table IV.

A 75\% improvement in the PASI score (PASI-75) is predominantly used to document the effectiveness of individual therapies in clinical trials of patients with extensive psoriasis. ${ }^{13}$ A DLQI of 10 or more correlates well with severe disease requiring admission, phototherapy or second-line therapy, and an improvement in DLQI of 5 or more points is considered a worthwhile criterion for response.

One should keep in mind that marked cross-cultural inequivalence exists in these tools to measure quality of life impact, ${ }^{12}$ no tools for this purpose have been developed specifically for South African cultural groups.

\subsection{Quality of life}

Psoriasis may profoundly affect all aspects of patients' social and personal lives (including their work). The impact of psoriasis on a patient is not directly related to the overall area affected, or to other parameters of disease activity such as redness or thickness of plaques, but more to the site distribution and the attitude of the patient. It is important to be able to measure the handicap caused by psoriasis for use

Table IV. Measures of psoriasis severity ${ }^{14}$

- Psoriasis Area and Severity Index (PASI). The PASI is a measure of overall psoriasis severity and coverage that assesses body surface area, erythema, induration and scaling ${ }^{13}$

- Body surface area (BSA) affected

- Overall Lesion Severity Scale (OLS)

- Physician's Global Assessment (PGA)

- Health-related Quality of Life (HRQL)

- Dermatology Life Quality Index (DLQI) in clinical trials, for audit purposes and to aid clinical decision taking.

\subsection{How do we define the severity of psoriasis?}

All existing disease severity assessment tools are imperfect and most require some training to complete. There is currently no universally accepted definition of what constitutes mild, moderate and severe psoriasis, nor can there be a concise and clinically meaningful definition given the broad clinical spectrum.

BSA of involvement is not an adequate parameter. The PASI score, severity of individual lesions, localisation of lesions, symptoms, functional impairment, effect on quality of life of the patient, and response to and side-effects of previous treatment also have to be taken into account.

The Working Group considered the existing definitions ${ }^{14-18}$ of moderate to severe psoriasis and concluded that the burden psoriasis presents to the patient is often underestimated by physicians and regulatory authorities, as is the extent to which current treatments influence patients' quality of life.

The Working Group made recommendations for the defining criteria of psoriasis severity (Table V).

\section{Referral (Table VI)}

Referral to a dermatologist should be considered in the following instances:

- Patients with extensive disease who need secondary care treatments. The dermatologist should also be involved in the care of difficult cases where the site or unresponsiveness of the rash are important factors.

- Diagnostic uncertainty.

- Request for further counselling and/or education, including demonstration of topical treatment.

- Failure of appropriately used topical treatment for a reasonable time (e.g. 2 - 3 months).

- Extensive disease, if unresponsive to initial therapy or difficult to self-manage.

- Need for increasing amounts or potencies of topical corticosteroids.

- Involvement of sites which are difficult to treat, e.g. face, palms and soles, genitalia, if unresponsive to initial therapy.

- Need for systemic therapy, phototherapy (e.g. guttate psoriasis), day treatment or inpatient admission.

- Generalised erythrodermic or generalised pustular psoriasis (emergency referral is indicated), or acute unstable psoriasis (urgent referral may be justified).

- Adverse reactions to topical treatment.

- Occupational disability or excessive time off work or school.

\subsection{Content of the referral letter (Table VII)}

The referral letter should include:

- The reason for referral and what is hoped to be gained from the consultation (the consultant should try to address these issues in reply).

- The patient's present therapy (if any), its duration and the quantity being used. 
Table V. Defining criteria of psoriasis severity

\begin{tabular}{ll}
\hline Mild psoriasis & Moderate to severe psoriasis \\
\hline Generally $<5 \%$ of BSA affected & $\geq 10 \%$ BSA affected \\
Disease does not alter the quality of life of the patient & $<10 \%$ BSA affected with very thick, red and/or scaly plaques \\
Effective treatment has no serious side-effects & $<10 \%$ BSA affected and resistant to topical therapy \\
& Psoriasis causing a significant impact on quality of life: \\
& Functional impairment involving hands or feet \\
& Marked pruritus \\
& Marked discomfort \\
& Psoriasis in certain locations significantly impacting on quality of life and \\
& self-esteem irrespective of $\%$ BSA affected \\
\hline
\end{tabular}

\section{Table VI. Criteria for referral to a dermatologist}

- Extensive disease

- Need for systemic treatment or phototherapy

- Diagnostic uncertainty

- Further counselling/education

- Failure of topical therapy (2 - 3 months)/adverse reactions to topical therapy

- Increased amount or potencies of topical corticosteroids

- Difficult-to-treat areas

- Need for day treatment or inpatient admission

- Generalised erythrodermic/pustular psoriasis (emergency referral)

- Acute unstable psoriasis (urgent referral)

- Occupational/school absence or disability

\section{Table VII. Content of the referral letter}

- Reason for referral

- Current therapy

- Previous therapy (responses or side-effects)

- General medical health

- Any other current medication

- Home circumstances

- Information on previous therapy, including responses or side-effects (a treatment could be mistakenly recorded as ineffective when the real problem was under-treatment or incorrect use of the prescribed treatment, or discontinued as unsuitable when transient side-effects could have been overcome had more advice been given).

- Any relevant background information, including the patient's general health and current medication.

- The patient's home circumstances. This is important as the patient's ability to apply topical therapies at affected sites may be compromised, affecting treatment choice.

\section{What is the current treatment paradigm?}

Treatment paradigms are conventionally based on the morphological type and severity of psoriasis.

For moderate to severe plaque psoriasis, many practitioners believe in the traditional strategy, commonly depicted as a stepwise paradigm starting with topical agents followed by phototherapy and then systemic agents. ${ }^{10,11,16}$ The physician must deem a step ineffective before progressing to the next step.

First-line systemic treatment may be indicated if topical therapy is impractical. ${ }^{1}$ More recent versions of the stepwise model (Table VIII) incorporate biologicals into the same category as other systemic agents and recommend that they be considered as first-line therapies alongside conventional systemic agents. ${ }^{12}$

\subsection{Shortcomings of the conventional treatment paradigm}

The Working Group considered both the shortcomings of the stepwise treatment paradigm and potential areas for improving the current recommendations for the care of patients, and concluded that there was an unmet need in the management of moderate to severe psoriasis.

The therapy(ies) selected by the patient with the advice of their physician must take into account the following aspects:

\section{Disease}

- The type of psoriasis present in the patient

- Location of lesions: face, ears, hands, feet, genitalia and intertriginous areas, scalp, nails, trunk, extremities

- Severity of the lesions: thickness, redness, scaling

- Symptoms: pain, pruritus, other

- Extent of disease, BSA estimates; PASI score

- Joint involvement.

\section{Patient}

- Age of the patient

- Quality of life considerations: ability to perform daily activities, employability, interpersonal relationships

- Co-morbid disease/disease states including childbearing potential, pregnancy, desire to impregnate, liver disease, hepatitis $\mathrm{C}$ or HIV infection, hypertension, metabolic syndrome and alcohol intake.

\section{Treatment}

- Response to previous therapies

- Accessibility to dermatologist, hospital, ultraviolet (UV) light facilities

- Therapies available to treating physician, and physician preferences and experience.

Table VIII. Conventional step-wise treatment paradigm

\begin{tabular}{lll}
\hline Step 1 & Step 2 & Step 3 \\
\hline Topical agents & Phototherapy & $\begin{array}{l}\text { Systemic agents } \\
\text { Biologicals }\end{array}$ \\
\hline
\end{tabular}




\section{Economic}

- Economic factors relating to therapy options, e.g. cost/ benefit ratios, potential for third-party insurers to approve the plan for treatment

\subsection{What are the unmet needs for treatment of patients with moderate to severe psoriasis? (Table IX)}

There is a need for improved education on the negative physical and HRQL impact on patients and physicians (e.g. physical, emotional and social impact). To help patients come to terms with what is, for many, a lifelong condition, great efforts should be made to improve communication during consultations and to educate patients.

Patients should have a plan of management, including the therapeutic options for the treatment of their psoriasis at each site involved, and verbal and written information on the probable benefits and possible side-effects of each therapy, enabling them to make an informed decision about the treatment.

Ideally practical demonstrations of the application of treatment should be offered by appropriately trained members of a primary health care team.

An introduction to patient support groups may be helpful.

\section{Current therapeutic options}

Therapeutic options for psoriasis range from topical treatment to phototherapy and systemic agents, including biologicals (Fig. 1). The choice of therapy is determined in part by the severity of the illness. Each of these therapeutic options will be discussed in depth, highlighting the current evidence supporting their efficacy and safety, their practicality for patient and physician, and general recommendations for their use. $^{13,32,33}$

The various therapeutic options will now be discussed by treatment class. This section of the guidelines has been adapted with written permission from the authors of the German Guidelines for Psoriasis. ${ }^{32,33}$

\subsection{Topical therapy}

Evidence has shown that the selection of treatment for patients with psoriasis vulgaris is more commonly based on traditional concepts than evidence-based data on the efficacy of various therapeutic options. This section of the guidelines provides explanations of available topical treatments, as well as different photo- and photochemical therapies, for psoriasis. They are based on the German evidence-based guidelines for the

\section{Table IX. Unmet needs of treatment}

- Long-term sustainable relief ${ }^{19-21}$

- Safe and convenient control ${ }^{11,22-27}$

- Individualised treatment tailored to patients' needs ${ }^{1,19,28}$

- Patient satisfaction with current therapy ${ }^{29}$

- Increased recognition of HRQL issues ${ }^{30,31}$

- Improved education on psoriasis treatment of psoriasis vulgaris, modified and adapted where applicable for the South African context. ${ }^{32,33}$

The aim of the guideline is to provide a tool that enables the physician to select an appropriate treatment for each individual patient on the basis of evidence-based studies rather than personal experience or traditional therapeutic concepts. For this purpose a total of 6224 publications were evaluated and data used where appropriate.

The currently available topical treatments are summarised in Table X, which provides an overview of the evaluation of therapeutic options. The various therapeutic options are then discussed in more detail.

\subsubsection{Topical corticosteroids (Table XI) ${ }^{33}$}

\section{General assessment}

With the application of potent corticosteroids (betamethasone diproprionate, twice daily), $46-56 \%$ of patients show a clear improvement or a complete clearing of skin lesions. Therapy with very potent corticosteroids (clobetasol-17-propionate, twice daily) demonstrated similar results in $68-89 \%$ of patients in most studies.

Topical corticosteroids demonstrate good to very good efficacy in the treatment of mild to moderate psoriasis. Combination with salicylic acid enhances the therapeutic effect. Combination with other systemic or topical therapies also results in improved rates of remission. The most common combination is with topical vitamin $\mathrm{D}_{3}$ derivates or tar.

There are no severe adverse drug reactions in the induction phase. Care must be taken regarding development of typical adverse corticosteroid effects such as skin atrophy or telangiectasia in cases of longer use and in particularly sensitive areas. The practicality for physicians and patients is good.

\section{Therapeutic recommendation}

- Therapy with topical corticosteroids is highly recommended for mild to moderate psoriasis vulgaris as a combination therapy with systemic therapies or other topical therapies.

- The selection of the class of corticosteroids must be adjusted for the specific skin area to be treated.

- Long-term use must take safety aspects into account.

\subsubsection{Coal tar (Table XII) ${ }^{33}$}

\section{General assessment}

Since only one monotherapy study was evaluated (with 3 patients), it is not possible to make a clear statement about the efficacy of monotherapy (level of evidence (LE) 4). Coal tar has been used in clinical studies in combination with phototherapy.

In combination therapy with UV light, a reduction of the PASI by about $75 \%$ was achieved in $45-80 \%$ of study participants after 15 - 20 applications. The additional effect of coal tar in combination therapy with UV compared with UV therapy alone has not been proven. 


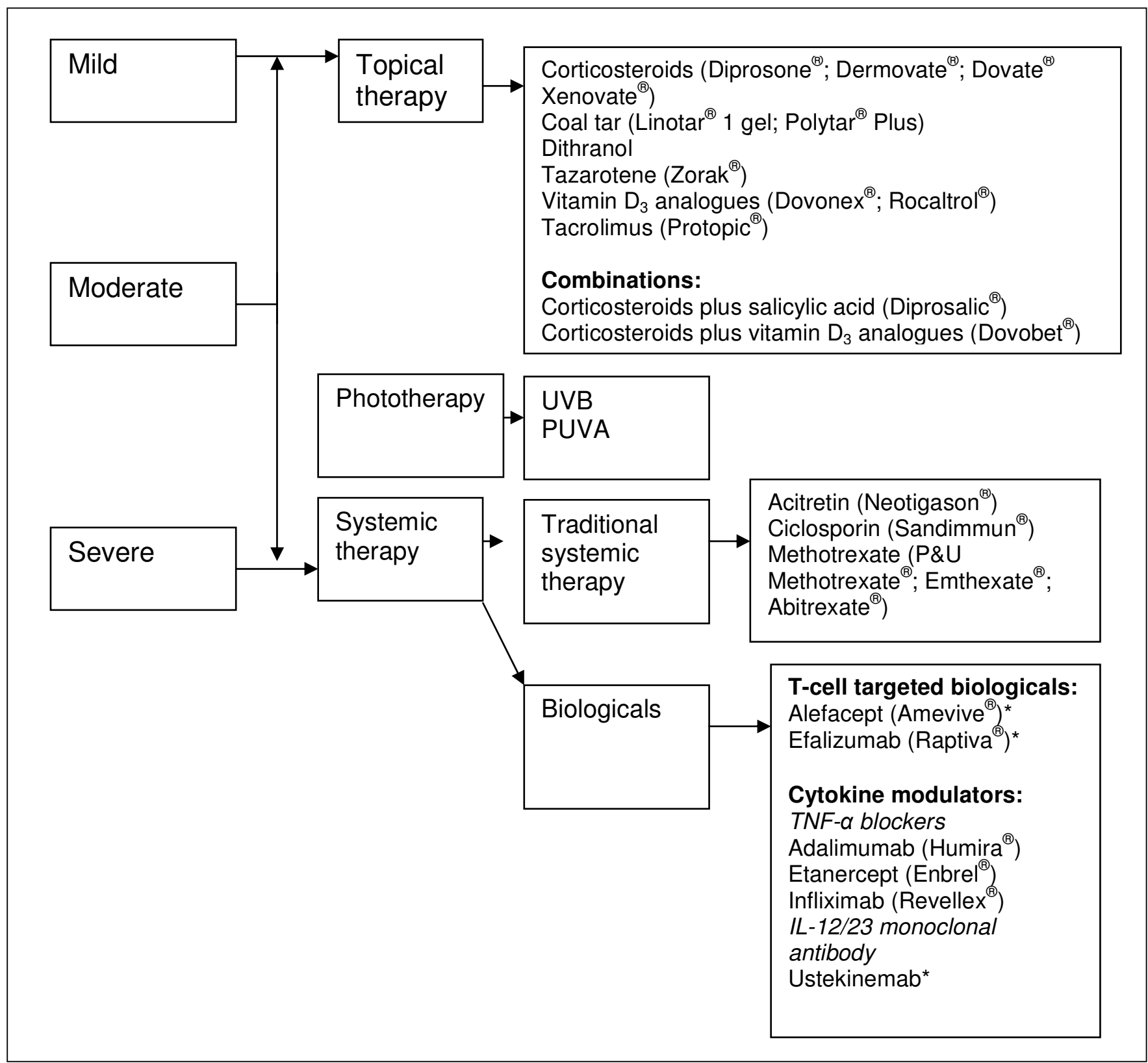

Fig. 1. Overview of current therapeutic options in psoriasis (adapted with written permission from the German Guidelines for Psoriasis ${ }^{32,33}$ ). ${ }^{*}$ Products not currently registered in South Africa.

\section{Therapeutic recommendation}

- Although the efficacy of coal tar in the treatment of psoriasis as monotherapy has not been demonstrated, it is an inexpensive alternative in some patients.

- It can also be used in combination with phototherapy (UVB).

\subsubsection{Dithranol (Table XIII) ${ }^{33}$}

\section{General assessment}

The results of the studies assessed showed total remission (PASI reduction 100\%) in $30-70 \%$ of patients and partial remission (PASI reduction $75 \%$ ) in $26-100 \%$ after 5 - 8 weeks of treatment (LE 2). The efficacy can be improved further if either calcipotriol creams or UVB phototherapy are combined with dithranol.

\section{Therapeutic recommendation}

- Short-duration therapy should be given preference because it is more practical.

- In hospitalised patients, classic dithranol therapy with twice-daily application without immediate rinsing can easily be performed.

- The therapy should be performed for 4 weeks and conditionally recommended as an outpatient treatment for 4 - 8 weeks.

- Maintenance or long-term therapy with dithranol is not practical and offers no advantages.

- In the treatment of severe forms of psoriasis, combination treatment with phototherapy or other topical preparations (calcipotriol) is recommended because of the improved response rate. 


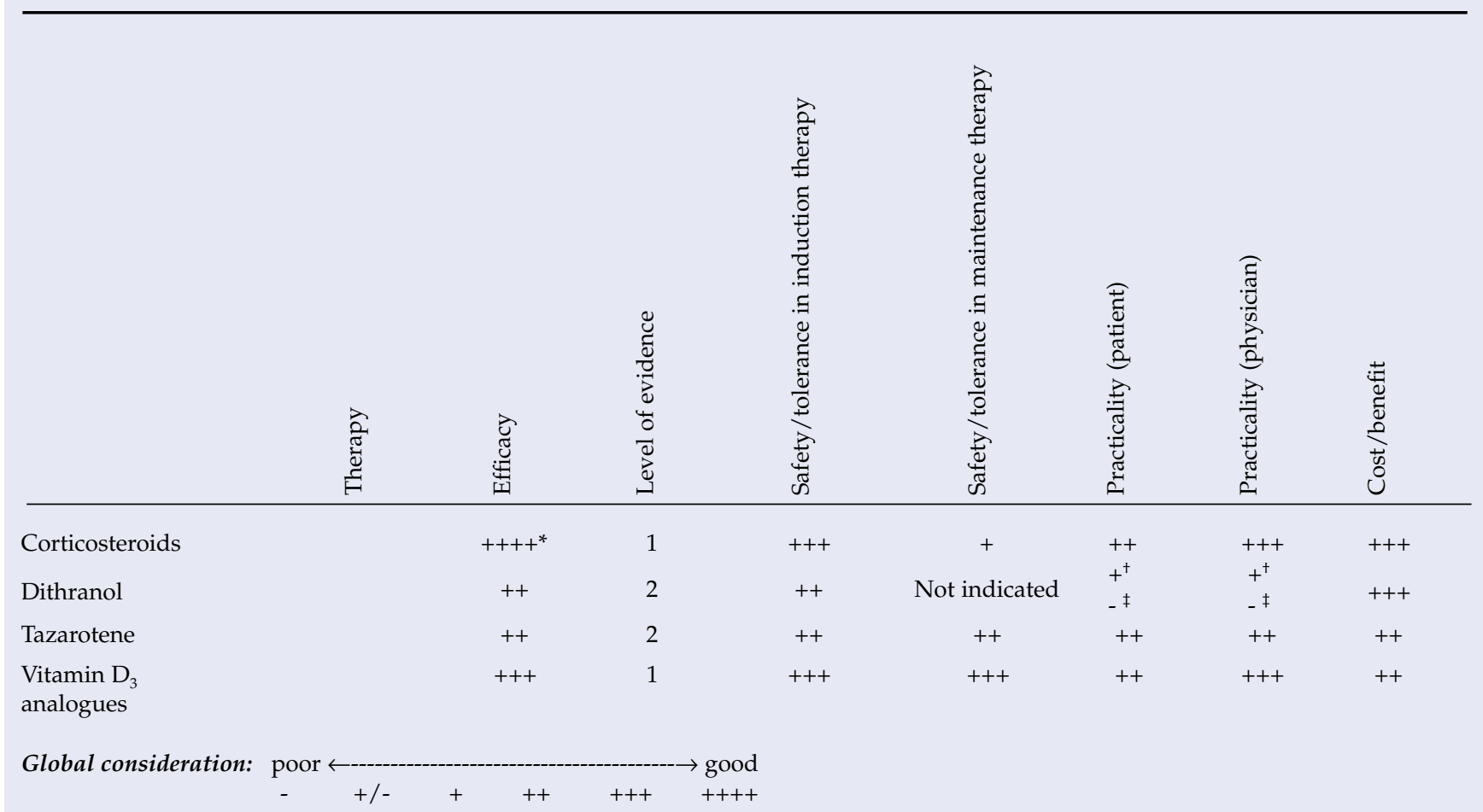

Efficacy. The evaluation of the efficacy column reflects the percentage of patients who achieved a reduction in the baseline Psoriasis Area and Severity Index (PASI) of $\geq 75 \%$ (++++ approx. $60 \%$;+++ approx. $45 \%$; ++ approx. $30 \%$; + approx. $15 \%$; +/- approx. $10 \%$; - not defined). The evidence level applies only to the estimate of efficacy.

Safety/tolerance on induction therapy or maintenance therapy. This refers to the risk of occurrence of severe adverse drug reactions or the probability of adverse drug reactions that would result in the discontinuation of therapy.

Practicality (patient). This evaluation analyses the effort involved in handling and administrating the treatment regimen by the patient.

Practicality (physician). This aspect considers the amount of work (documentation, explanation, monitoring), personnel and equipment needs, time for physician/patient interaction, remuneration of therapeutic measures, invoicing difficulties/risk of recourse claims from the health insurance companies.

Cost/benefit. Consideration for the costs of an induction therapy, or a maintenance therapy.

The evaluations of safety/tolerance in induction therapy or maintenance therapy as well as practicality for the physician or patient and the cost/benefit were performed using a scale ranging from poor (-) to good (++++). The gradation between these two extremes was made based on expert opinion and unsystematic literature search. A level of evidence was not given for these evaluations, since no systematic literature review was performed.

*Potent (e.g. betamethasone) or very potent corticosteroid (e.g. clobetasol), also valid for fixed combinations (vitamin D plus potent corticosteroids). tInpatient.

†Outpatient.

Table XI. Summary, topical corticosteroids

Recommended control parameters Recommended initial dosage

Recommended maintenance dosage Expected beginning of clinical effect Response rate

Important contraindications Important adverse reactions

Important drug interactions

Ler
None

Once or twice daily

Gradual reduction following onset of effect

After 1 - 2 weeks

Betamethasone dipropionate, twice daily: marked improvement or clearance of the skin lesions in $46-56 \%$ patients after 4 weeks (LE 1)

Skin infections, rosacea, peri-oral dermatitis

Skin infections, peri-oral dermatitis, skin atrophy, hypertrichosis, striae

None 


\begin{tabular}{|c|c|}
\hline Recommended control parameters & $\begin{array}{l}\text { After long-term application/application on large areas: if needed } \\
\text { clinical controls for potential development of skin carcinoma }\end{array}$ \\
\hline Recommended initial dosage & $5-20 \%$ ointment preparations or gels for local therapy, once daily \\
\hline Recommended maintenance dosage & No long-term application (max. 4 weeks) \\
\hline Expected beginning of clinical effect & $\begin{array}{l}\text { After } 4 \text { - } 8 \text { weeks, efficacy improves in combination with UV } \\
\text { application }\end{array}$ \\
\hline Response rate & $\begin{array}{l}\text { There are insufficient data available on the response rate as a } \\
\text { monotherapy (LE } 4 \text { ) } \\
\text { Combination with topical steroids }(10-50 \%) \text { and salicylic acid } \\
\text { enhances efficacy }\end{array}$ \\
\hline Important contraindications & Pregnancy and breastfeeding \\
\hline Important adverse reactions & $\begin{array}{l}\text { Colour, odour, carcinogenic risk, phototoxicity (which is part of the } \\
\text { desired effect) }\end{array}$ \\
\hline Important drug interactions & Not known with topical use \\
\hline
\end{tabular}

\section{Table XIII. Summary, dithranol}

Recommended control parameters

Recommended initial dosage

Recommended maintenance dosage

Expected beginning of clinical effect

Response rate

Important contraindications Important adverse reactions Important drug interactions

\section{Intensity of irritation}

Begin with $0.5 \%$ preparation for long-term therapy or $1 \%$ for shortcontact therapy, then increase if tolerated

Not recommended for maintenance therapy

After 2 - 3 weeks

Marked improvement or clearance of skin lesions in $30-50 \%$ of patients (LE 2)

Acute, erythrodermic forms of psoriasis; pustular psoriasis Burning and reddening of the skin in $>10 \%$
Dithranol, one of the oldest topical therapeutics for psoriasis, is still a treatment for mild to moderate psoriasis as outpatient monotherapy and as part of combination therapies for moderate psoriasis in hospitalised and day clinic patients.

The therapy is very safe. Although skin irritation, burning, erythema and intermittent brown discolorations are observed, there are no systemic adverse reactions. The practicality is limited in outpatient use, due to these events, and the introduction of newer topical agents. However, the practicality for the physician, especially when treating inpatients, and the cost/benefit ratio are positive.

\subsubsection{Tazarotene (Table XIV) ${ }^{33}$}

\section{General assessment}

After daily treatment with tazarotene $0.1 \%$, approximately $50 \%$ of patients showed at least a $50 \%$ improvement of the skin lesions after about 12 weeks of treatment (LE 2). Therapeutic success and reduction of the frequent skin irritations can be optimised with a combination of tazarotene and topical corticosteroids. There are no severe adverse reactions. However, contact with healthy skin should be avoided to prevent skin irritation.

\section{Therapeutic recommendation}

- The topical application of tazarotene is recommended for the treatment of mild to moderate psoriasis.

- An application of tazarotene in the evening in combination with a corticosteroid in the morning is recommended as a combination therapy to reduce irritation and increase efficacy.

\subsubsection{Vitamin $\mathrm{D}_{3}$ analogues (Table $\left.\mathrm{XV}\right)^{33}$}

\section{General assessment}

The majority of available data are on calcipotriol. After $\mathrm{D}_{3}$-analogue treatment of mild to moderate psoriasis, $30-50 \%$

\section{Table XIV. Summary, tazarotene}

Recommended control parameters

Recommended initial dosage

Recommended maintenance dosage Expected beginning of clinical effect Response rate

Important contraindications Important adverse reactions Important drug interactions
Check development of skin irritation

Begin with one treatment daily of tazarotene gel $0.05 \%$ in the evening for approximately $1-2$ weeks

If necessary continue for 1 - 2 weeks with tazarotene gel $0.1 \%$ After 1 - 2 weeks

After 12 weeks' therapy with $0.1 \%$ tazarotene gel there was at least $50 \%$ improvement in approximately $50 \%$ of patients (LE 2 )

Pregnancy and breastfeeding

Pruritus, burning sensation of skin, erythema, irritation

Avoid concomitant use of preparations with irritating and drying properties 
Table XV. Summary, vitamin $\mathrm{D}_{3}$ analogues

Recommended control parameters

Recommended initial dosage

Recommended maintenance dosage

Expected beginning of clinical effect

Response rate

Important contraindications

Important adverse reactions

Important drug interactions

Other
Monitor for skin irritation

Calcipotriol: Once or twice daily to affected locations, up to a maximum of $30 \%$ of body surface

Tacalcitol: Once daily to affected locations, up to a maximum of $20 \%$ of body surface

Calcitriol: Twice daily to affected locations, up to a maximum of $35 \%$ of body surface

Calcipotriol: Once or twice daily, up to $100 \mathrm{~g} / \mathrm{wk}$ for up to 1 year Tacalcitol: Once daily for 8 weeks, for up to 18 months, on a maximum of $15 \%$ of body surface with up to $3.5 \mathrm{~g} / \mathrm{d}$

Calcitriol: Insufficient experience with application for more than 6 weeks

After 1 - 2 weeks

Between $30 \%$ and $50 \%$ of patients demonstrated a marked

improvement or clearance of the lesions after 4 - 6 weeks (LE 1)

Diseases with abnormal calcium metabolism, severe liver and renal diseases

Skin irritation (reddening, itching, burning)

Drugs that elevate the calcium levels (e.g. thiazide diuretics), no concomitant application of topical salicylic acid preparations (inactivation)

Exposure to UV light results in inactivation of the vitamin $\mathrm{D}_{3}$ analogues of patients showed a marked improvement or clearance of the skin lesions within a few weeks (LE 1).

Efficacy and tolerance can be improved further if the vitamin $\mathrm{D}_{3}$ analogue is combined with topical corticosteroids during the initial therapy. In the treatment of severely affected patients, topical therapy with vitamin $\mathrm{D}_{3}$ analogues demonstrated synergistic effects with UV phototherapy and systemic ciclosporin therapy.

The topical vitamin $D_{3}$ analogues are generally well tolerated and practical for the physician and the patient. Temporary skin irritation may limit use, especially on the face or the intertriginous areas.

\section{Therapeutic recommendation}

- Vitamin $\mathrm{D}_{3}$ analogues are the treatment of choice for maintenance therapy in mild to moderate psoriasis.

- On the basis of the extensive study data and superior efficacy, this recommendation is particularly true for calcipotriol.

- The application of tacalcitol is particularly recommended for sensitive areas (e.g. face), owing to its low irritation potential.

- In the first weeks, combined use together with topical corticosteroids or as a fixed combination is superior to monotherapy with respect to efficacy and tolerance.

- For moderate to severe psoriasis, a combination of topical vitamin $\mathrm{D}_{3}$ analogues with UV phototherapy or as systemic therapy can be recommended.

\subsubsection{Tacrolimus ointment ${ }^{34}$}

- Tacrolimus ointment is effective for facial and intertriginous psoriasis.

- Topical tacrolimus appears relatively ineffective for the treatment of plaque-type psoriasis owing to poor penetration through the plaque.
- A thin layer of cream is applied to the affected areas twice a day.

- It is well tolerated and the only adverse effect is occasional pruritus in the treated areas.

- Topical tacrolimus offers the potential for anti-inflammatory effect without the atrophy or local side-effects associated with the use of topical corticosteroids.

- It is therefore recommended for use in intertriginous or facial psoriasis.

\subsection{Phototherapy (Tables XVI and XVII)}

\section{General assessment}

About three-quarters of all patients treated with phototherapy attained at least a $75 \%$ PASI score reduction after 4 - 6 weeks, and clearance was frequently achieved (LE 2). Phototherapy represents a safe and very effective modality for the treatment of moderate to severe forms of psoriasis. The onset of the clinical effect is within 2 weeks.

Of the unwanted side-effects, UV erythema from overexposure is by far the most common and is frequently observed. With repeated or long-term application, the consequences of high, cumulative UV dosages (i.e. premature ageing of the skin) must be taken into consideration. In addition, carcinogenic risk is associated with oral psoralen + UVA photochemotherapy (PUVA) and is probable for local PUVA and UVB.

The practicality of the therapy is limited as a result of the spatial, financial and human aspects, as well as the amount of time required by both the physician and the patient. From the perspective of the cost-bearing institution, phototherapy has a good cost-benefit ratio. However, the potentially significant costs and time required of the patient must be noted.

\section{Instructions for application}

\section{Pre-treatment}

- The attending physician has to perform a complete skin 


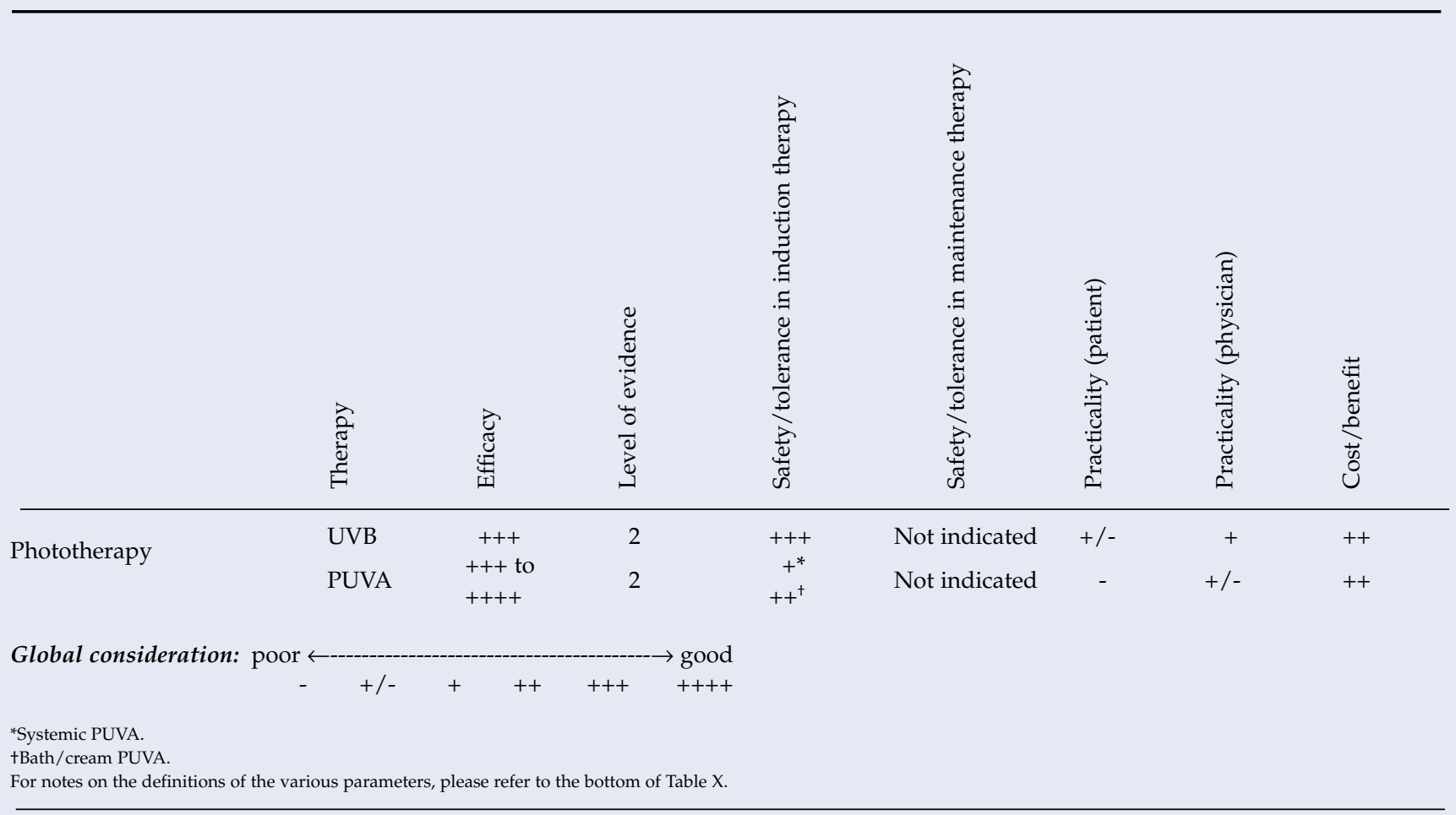

\section{Table XVII. Summary, phototherapy}

Recommended control parameters

Recommended initial dosage

Recommended maintenance dosage

Expected beginning of clinical effect Response rate

Important contraindications

Important adverse reactions

Important drug interactions

Other
Regular skin inspection (UV erythema)

Individual dose depends on skin type; options:

- UVB: $70 \%$ of minimum erythema dose (MED)

- Oral PUVA (photochemotherapy): $75 \%$ of the minimum phototoxic dose (MPD)

- Bath/cream PUVA: 20 - 30\% of MPD

Increase according to degree of UV erythema

After 1 - 2 weeks

In $>75 \%$ of the patients PASI- $75 \%$ after $4-6$ weeks (LE 2 )

Photo-dermatoses/photosensitive diseases, skin

malignancies, immunosuppression

Erythema, itching, blistering, malignancies

Only oral PUVA: nausea

Drugs causing phototoxicity or photo-allergy

In combination with topical preparations, acts synergistically; PUVA may not be combined with ciclosporin examination, paying special attention to melanocytic naevi (especially if dysplastic) and cutaneous malignancies.

- The patient must be informed about unwanted side-effects and possible long-term risks - especially the therapy-related increased risk of skin cancer. Additional UV exposure as a result of leisure-time activities should be considered.

- Before starting oral PUVA therapy, an ophthalmological examination and the prescription of UV sunglasses is required.

\section{During treatment}

- The UV dosages applied must be documented in precise physical units $\left(\mathrm{J} / \mathrm{cm}^{2}\right.$ or $\left.\mathrm{mJ} / \mathrm{cm}^{2}\right)$. Regular monitoring of UV erythema must be performed for the purpose of dosage increases.
- The medical records should document therapeutic response, unwanted side-effects, and accompanying treatments.

- Eye protection with UV glasses is generally required.

- If the areas chronically exposed to light (face, neck, backs of hands) and the genital region are free of lesions, these should be protected from exposure.

- Adequate protection from the sun must accompany therapy.

\section{Post-treatment}

- Whenever a course of therapy is completed, the cumulative UV dosage and the number of treatments should be recorded and the patient informed.

- Particularly in the case of patients with high cumulative UV dosage, regular skin cancer examinations should be performed for the rest of the patient's life. 


\section{Therapeutic recommendation}

- Phototherapy is recommended as an induction therapy for moderate to severe psoriasis, particularly for widespread involvement.

- The side-effects of specific types of radiation must be weighed up. A possible subsequent risk of skin cancer is better documented for PUVA than for UVB.

- Practicality and the association of long-term unwanted side-effects with cumulative UV doses must be taken into account in long-term treatment. Combination with topical vitamin $\mathrm{D}_{3}$ analogues is recommended to improve the response rate.

- A recommendation for the common combination with tar, dithranol and corticosteroids can only be given on the basis of clinical experience, but not on the basis of scientific data.

\subsection{Excimer laser}

- Excimer laser is recommended for the targeted treatment of individual psoriatic plaques only.

- The $308 \mathrm{~nm}$ excimer laser can be administered to precisely targeted diseased skin, leaving healthy skin unexposed.

- The cumulative UVB dosage is therefore lower than conventional UV treatment.

- Practicality is limited as a result of financial aspects as well as time resources on the part of the patient and physician.

\subsection{Systemic therapy}

The recommendations in these guidelines will be presented according to the level of evidence (Table XVIII) and grade of recommendation (Table XIX) currently available for each systemic agent. The symbols used to indicate these are explained in the above tables.

\subsubsection{Acitretin (oral retinoids) (Table XX) \\ Background}

Vitamin A (retinol) and its derivatives (retinoids) modulate keratinocyte differentiation and proliferation, but the exact mechanism of action in psoriasis has not been fully elucidated. Early use of retinoids involved supra-physiological dosing with vitamin A, causing hypervitaminosis A syndrome. Synthetic retinoids, etretinate (Tigason ${ }^{\circledR}$ ) and acitretin (Neotigason ${ }^{\circledR}$ ) were developed to overcome this side-effect. Acitretin is the only product currently available in South Africa for use in psoriasis and the only one included in these guidelines. Isotretinoin (Roaccutane ${ }^{\circledast}$, Oratane ${ }^{\circledR}$ ), used for acne treatment, is much less effective for psoriasis than acitretin. Retinoids are teratogenic and hepatotoxic but not immunosuppressant. ${ }^{35}$

\section{Evidence of efficacy}

Plaque psoriasis

A systematic review ${ }^{36}$ revealed 11 randomised controlled trials (RCTs) in which acitretin was used to induce remission and/or remission maintenance for psoriasis. The heterogeneous nature of the data made data pooling and analysis difficult. Despite its teratogenicity and the high incidence of symptomatic mucocutaneous side-effects, it was moderately effective as monotherapy at doses of $1 \mathrm{mg} / \mathrm{kg} / \mathrm{d}(75 \mathrm{mg} / \mathrm{d})$ compared with placebo, but was less effective than ciclosporin. Used in combination with PUVA, acitretin was more effective than monotherapy. There was insufficient evidence on the use of retinoids as long-term maintenance therapy.

A later evidence-based review ${ }^{37}$ included 5 reports on acitretin as monotherapy and confirmed that acitretin was superior to placebo at $1 \mathrm{mg} / \mathrm{kg} / \mathrm{d}(75 \mathrm{mg} / \mathrm{d})$, but $2 \mathrm{RCTs}$ involving 286 people indicated that retinoids were less effective than ciclosporin at inducing remission in $10-12$ weeks.

Combination therapies were more effective than monotherapy. In combination with PUVA (6 series; $N=286$ ) acitretin combined

\section{Table XVIII. Levels of evidence}

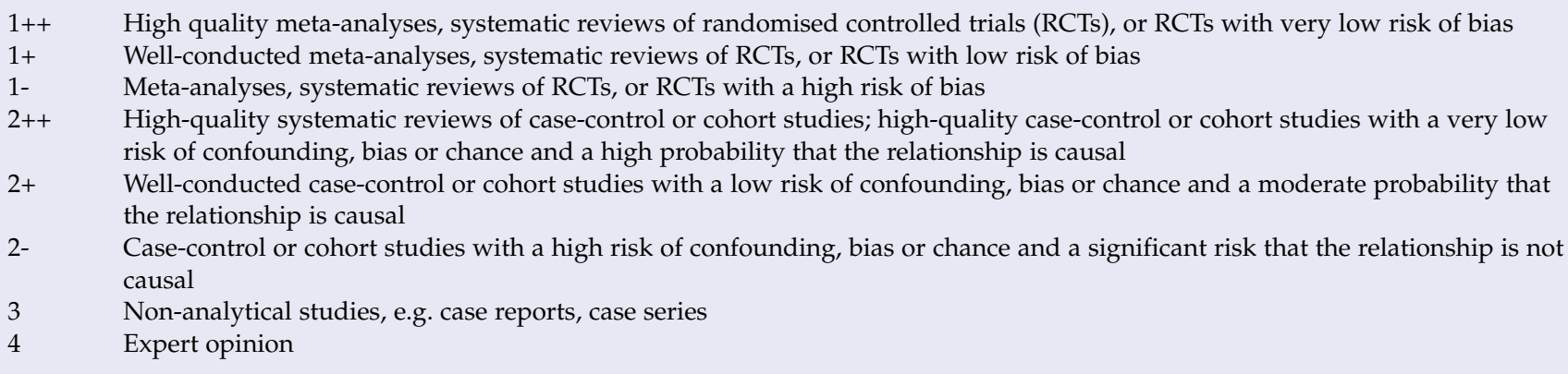

\section{Table XIX. Grades of recommendation}

A At least one meta-analysis, systematic review or RCT rated as 1++ and directly applicable to the target population; or a
systematic review of RCTs or a body of evidence consisting principally of studies rated as $1+$, directly applicable to the target
population and demonstrating overall consistency of results
A body of evidence including studies rated as $2++$, directly applicable to the target population and demonstrating overall
B
consistency of results; or extrapolated evidence from studies rated as $1++$ or $1+$
A body of evidence including studies rated as $2+$, directly applicable to the target population and demonstrating overall
consistency of results; or extrapolated evidence from studies rated as $2++$
D $\quad$ Evidence level 3 or 4 ; or extrapolated evidence from studies rated as $2+$
Not recommendable




\section{Table XX. Summary, acitretin (1- ; C)}

Recommended control parameters Recommended dosage

Efficacy

Important contraindications

Important adverse reactions

Important drug interactions

Level of evidence

Strength of recommendation Other
Pregnancy testing, contraception use, plasma lipids, transaminases and skeletal X-rays Individual dosing dependent on the results, tolerability and concomitant medications used

$1 \mathrm{mg} / \mathrm{kg} / \mathrm{d}$ to a maximum of $75 \mathrm{mg} / \mathrm{kg} / \mathrm{d}$

Monotherapy

More effective than placebo but less effective than ciclosporin (at a dose of $75 \mathrm{mg} / \mathrm{d}$ ) ${ }^{36}$ Combination therapy ${ }^{37}$

- More effective in combination with PUVA than PUVA alone

- More effective in combination with UVB than UVB alone

- More effective than acitretin alone when used in combination with corticosteroids or calcipotriol

Effective for erythrodermic and pustular psoriasis ${ }^{40}$

May be effective for psoriatic arthritis ${ }^{41}$

Consider in immunosuppressed (cancer or HIV) patients ${ }^{35}$

Teratogenicity

A teratogen (category $\mathrm{X}$ ) for women of childbearing age

Because of its long half-life, contraception must be used for a minimum of 2 years after discontinuing its use

\section{Mucocutaneous side-effects}

These occur in most patients taking acitretin (they are features of hypervitaminosis A, and are dose-dependent and reversible)

Most common: dry mucosa, alopecia, skin peeling, dermatitis

Less common: Paronychia, skin stickiness and skin and nail fragility

Liver dysfunction and musculoskeletal adverse effects

- Increased triglycerides can be noted in up to $25 \%$ of patients and need to be monitored

- Hepatotoxicity is rare, minor or transient elevation of transaminases may be documented more commonly

- Arthralgias and myalgias may occur

- With long-term use bone toxicity has been described

Methotrexate (hepatotoxin), tetracyclines (pseudotumour cerebri), vitamin A supplementation (hypervitaminosis A syndrome), alcohol, phenytoin, progestin-only contraceptive pill, glibenclamide ${ }^{38,42}$

$1-$

C

Contraception must be used for a minimum of 2 years after discontinuation of acitretin in female patients of childbearing age

No blood donations should be made during and for a minimum of 2 years after stopping acitretin use with PUVA (rePUVA) was marginally more effective than PUVA alone, and there was a trend for a lower accumulative UVA dose with the combination. Similar findings were shown for the UVB combination ( 3 RCTs; $N=149$ ) compared with UVB alone. In combination with topical corticosteroids (2 series; $N=160$ ) and topical calcipotriol (2 studies; $N=221$ ), the combination was more effective than monotherapy with acitretin.

The German evidence-based guidelines ${ }^{33}$ had only 4 studies meeting inclusion criteria for monotherapy and 4 studies for combination therapy. They concluded that the evidence for the effectiveness of acitretin as combination or monotherapy was poor owing to heterogeneous study results and do not recommend its routine use.

Retinoids may be less effective than other systemic agents as monotherapy for short-term management of moderate to severe chronic plaque psoriasis, but they are effectively used in combination with phototherapy and topical agents or for longterm maintenance of clearance induced with other agents. ${ }^{35,38}$

Clinical data suggest that retinoids are effective for erythrodermic psoriasis control. ${ }^{35,38,39}$ Acitretin should be considered for those patients with co-morbidities contraindicating immunosuppression, such as cancer and HIV co-infection, as it is not an immunosuppressant. ${ }^{35}$

\section{Pustular psoriasis}

A systematic review of chronic palmoplantar pustulosis interventions found established but modest evidence to support the use of oral retinoid monotherapy for the induction and maintenance of remission. Efficacy was equal to that of oral PUVA. Combined oral retinoid and PUVA (rePUVA) was more effective than either intervention used alone. ${ }^{40}$

\section{Psoriatic arthropathy}

Effectiveness for psoriatic arthritis, compared with placebo, has been shown in one small trial summarised in a systematic review. ${ }^{41}$

\section{Adverse effects}

Acitretin use is associated with a large number of side-effects and toxicity reactions (Table XX). Compared with other systemic interventions for severe psoriasis, the potential for serious harm appears to be less. ${ }^{35,38,39}$ 


\section{Therapeutic recommendation}

- Despite the poor recommendation as short-term monotherapy for chronic plaque psoriasis remission induction, acitretin is effective when used in combination with phototherapy and topical agents, or for the longterm maintenance of remission/clearance induced by other systemic agents.

- Acitretin is effective for the pustular and erythrodermic variants of psoriasis.

- Acitretin may be effective for psoriatic arthritis.

- Acitretin should be considered for those patients with co-morbidities where immunosuppression is contraindicated, such as those with cancer and HIV co-infection, as it is not an immunosuppressant.

- Acitretin is a teratogen and is not recommended for women of childbearing age. Because of its long half-life, contraception must be used for a minimum of 2 years after stopping acitretin use, and no blood donations are possible for this time period either.

\subsubsection{Ciclosporin (Table XXI)}

\section{Background}

Ciclosporin (Sandimmun ${ }^{\circledR}$ ) is a calcineurin phosphatase antagonist and inhibits T-cell activation. A direct effect on keratinocytes has also been suggested. It is an immunosuppressant with significant renal toxicity, but is not teratogenic or myelosuppressant. ${ }^{35,36}$

\section{Evidence of efficacy}

Plaque psoriasis

A systematic review ${ }^{36}$ included 18 RCTs for ciclosporin remission induction efficacy (13 reports) and maintenance of remission efficacy ( 5 reports) for severe plaque psoriasis. The data were too heterogeneous for pooling (severity, dose, success criteria and duration of treatment), but favoured ciclosporin over placebo. Optimal remission induction responses were found for doses of $2.5-5.0 \mathrm{mg} / \mathrm{kg} / \mathrm{d}$, but higher doses, although more efficacious, were associated with more side-effects. The formulation (Sandimmun ${ }^{\circledR}$ v. Neoral ${ }^{\circledR}$ ) did not affect efficacy in the long term, but the emulsion produced a more rapid initial response. Doses of 3.0 - 3.5 $\mathrm{mg} / \mathrm{kg} / \mathrm{d}$ given continuously were needed for maintenance of remission. Comparative studies showed that low-dose ciclosporin was more effective than low-dose retinoids. Combined with calcipotriol, efficacy was enhanced.

A later systematic review ${ }^{43}$ included an additional RCT comparing ciclosporin and methotrexate as a monotherapy for moderate to severe plaque psoriasis, which is reviewed below.

Recently published RCTs have compared monotherapy ciclosporin with methotrexate $\mathrm{t}^{44-46}$ in moderate to severe plaque

Table XXI. Summary, ciclosporin (1+; A)

Recommended control parameters

Recommended initial dosage

Recommended maintenance dosage

Efficacy

Important contraindications

Important adverse reactions

Important drug interactions $\mathrm{s}^{36,42}$

Level of evidence

Strength of recommendation

Other

\section{General monitoring recommendations}

Full blood count, liver and renal functions, blood pressure (reduce dose or use nifedipine), serum potassium, HIV, hepatitis B and C

Renal monitoring recommendations ${ }^{48}$

Three baseline creatinine levels are recommended to calculate average pretreatment creatinine. Monitor weekly creatinine for increases in level from baseline. An increase of 30\% (maximum) above average pre-treatment level should be accompanied by a decreased dose in ciclosporin. If increase persists discontinue ciclosporin to prevent irreversible renal damage

$2.5 \mathrm{mg} / \mathrm{kg} / \mathrm{d}^{36}$

$3.0-3.5 \mathrm{mg} / \mathrm{kg} /$ day $^{36}$

Interval therapy dosing has been recommended to limit adverse effects Effective remission induction therapy in all types of psoriasis

Effective in moderate to severe plaque psoriasis and psoriatic arthritis Improves but does not clear palmoplantar pustulosis

Hypertension, renal disease, active chronic infections

History of malignancy

Pregnancy risk (category C)

Major toxic effects are hypertension, nephrotoxicity and immunosuppression Other side-effects include myalgia, arthralgia, nausea, diarrhoea, headache, gingival hyperplasia, paraesthesiae, tremor and hypertrichosis

Inducers of cytochrome P450 3A

Anticonvulsants (phenytoin, carbamazepine, phenobarbitone), rifampicin, sulphonamides

Inhibitors or substrates of cytochrome P450 3A

Macrolides, metronidazole, azoles, protease inhibitors, calcium channel blockers (diltiazem, verapamil, nicardipine), selective serotonin reuptake inhibitors, prednisone, grapefruit

Potentiate renal toxicity

Aminoglycosides, NSAIDs, vancomycin

$1+$

A

Increased risk of squamous cell carcinoma especially in those predisposed (skin phototype, previous sun damage, previous immunosuppressive therapy)

Increased risk of lymphoproliferative diseases in transplant patients ${ }^{33}$ 
psoriasis. Both ciclosporin (3 - $4 \mathrm{mg} / \mathrm{kg} / \mathrm{d}$ ) and methotrexate $(0.5 \mathrm{mg} / \mathrm{kg} / \mathrm{wk})$ were shown to be effective in a study from India $(N=30)$, but methotrexate appeared to produce more rapid and complete clearance. Side-effects were transient and minor. ${ }^{44}$ In contrast, there was no difference in efficacy, tolerability, rate of remission, time to remission or quality of life score in a study from the Netherlands $(N=88)$. Both ciclosporin $(3-5 \mathrm{mg} / \mathrm{kg} / \mathrm{d})$ and methotrexate $(15-22.5$ $\mathrm{mg} / \mathrm{wk}$ given as 3 doses every 12 hours) over 16 weeks resulted in a reduction in psoriasis severity index from baseline of $\geq 75 \%$ (PASI-75) in more than $60 \%$ of the patients. ${ }^{45} \mathrm{In}$ contrast, a study from Sweden $(\mathrm{N}=84)$ showed a $72 \%$ reduction in PASI (PASI-75 $=58 \%$ ) for ciclosporin $(3-5 \mathrm{mg} / \mathrm{kg} / \mathrm{d}$ ) compared with a $58 \%$ reduction in PASI (PASI-75 $=24 \%$ ) for methotrexate $(7.5-15 \mathrm{mg} /$ wk given as 3 doses every 12 hours with folate $5 \mathrm{mg} / \mathrm{d}$ on non-treatment days) over 12 weeks. There was no difference in quality of life and side-effects were common but tolerable. Although both drugs were effective, ciclosporin was more effective in the short-term treatment of moderate to severe chronic plaque psoriasis. ${ }^{46}$

The German guidelines ${ }^{33}$ had 15 studies meeting inclusion criteria for monotherapy. They concluded that there is good evidence and an acceptable risk/benefit ratio for ciclosporin as effective monotherapy for remission induction of moderate to severe plaque psoriasis, but advised caution with long-term use because of the renal side-effects.

A systematic review and meta-analysis of RCTs evaluating the efficacy (PASI-75) and tolerability (overall rate of withdrawal) of systemic treatments for moderate to severe psoriasis from Europe and North America, found 9 trials for ciclosporin meeting inclusion criteria. ${ }^{47}$ The response (PASI-75) ranged from $25 \%$ to $97 \%$, and the variability was only partly explained by variable dosing. Open-label studies had more patients reaching PASI-75 than did double-blind placebocontrolled trials. Ciclosporin (71.4\% PASI-75) was more effective than methotrexate (60.5\% PASI-75) after 16 weeks of treatment. Long-term efficacy (stable responses for $>10$ months) was reported in only one study. Owing to heterogeneity associated with an overestimation of efficacy in open-label studies, only double-blind placebo-controlled trials (3/9) of ciclosporin were included in the meta-analysis of 16 studies for biologicals. Ciclosporin (absolute risk difference (RD) $33 \%, 95 \%$ confidence interval (CI) $13-52 \%$ ) was less effective than infliximab (RD 77\%, 95\% CI $72-81 \%$ ), adalimumab (RD $64 \%, 95 \%$ CI $61-68 \%$ ) and high-dose (50 mg twice weekly) etanercept (RD $44 \%, 95 \%$ CI $40-48 \%$ ), but equivalent to or better than low-dose (25 mg twice weekly) etanercept (RD 30\%, 95\% CI 25 - 35\%) and efalizumab (RD 24\%, 95\% CI 19 - 30\%). Tolerability of ciclosporin was equivalent to the biologicals but better than methotrexate.

\section{Pustular psoriasis}

A systematic review of chronic palmoplantar pustulosis interventions found 2 trials for ciclosporin. ${ }^{40}$ Despite heterogeneous data, the authors concluded that there was good evidence for improvement, but not clearance, with short-term, low-dose ciclosporin use.

\section{Psoriatic arthropathy}

In a systematic review of psoriatic arthropathy interventions, no RCTs were available to evaluate the use of ciclosporin. ${ }^{41}$

\section{Adverse effects}

Ciclosporin is metabolised in the liver, so bio-availability and plasma levels are altered by drugs affecting the cytochrome P450 3A enzyme system.

Ciclosporin use is associated with a large number of sideeffects and toxicity reactions because of its narrow therapeutic index, low threshold for toxicity and plasma levels which are easily affected by inducers, inhibitors and substrates of cytochrome P450 3A. $33,36,38,42,43$ The incidence and severity of side-effects seen in patients with psoriasis correlates with the cumulative dose and/or duration of use. ${ }^{37}$

\section{Therapeutic recommendation}

- Ciclosporin is effective remission induction therapy for all types of psoriasis.

- Ciclosporin has equivalent but varying efficacy compared with methotrexate, dependent on the population and dose studied and the use of folate supplementation.

- Ciclosporin has been shown to be effective for moderate to severe plaque psoriasis when used at doses of $2.5-5$ $\mathrm{mg} / \mathrm{kg} / \mathrm{d}$.

- Ciclosporin improves but does not clear palmoplantar pustulosis.

- Common use confirms its effectiveness for psoriatic arthritis.

- Ciclosporin use is limited by the side-effect, drug interaction and contraindication profiles and monitoring required while on use.

\subsubsection{Methotrexate (Table XXII)}

\section{Background}

Methotrexate (P \& U Methotrexate ${ }^{\circledast}$, Emthexate $^{\circledR}$, Abitrexate $\left.^{\circledR}\right)$, a folic acid antagonist, is an anti-metabolite, which inhibits dihydrofolate reductase preventing nucleotide synthesis, nucleic acid synthesis and hence cell proliferation. Its mechanism of action in psoriasis is unknown. It was thought to have a direct effect on keratinocyte proliferation, but current views link it to T-cell function. It is hepatotoxic, myelosuppressant and teratogenic..$^{35}$

\section{Evidence of efficacy}

Plaque psoriasis

A systematic review ${ }^{36}$ revealed no randomised controlled trials (RCTs) in which methotrexate efficacy could be evaluated, despite its widespread use and supporting published studies suggesting a significant effect. A later systematic review of treatments for moderate and severe plaque psoriasis ${ }^{43}$ included 2 RCTs for methotrexate as monotherapy, which are reviewed below. Published RCTs have compared methotrexate with ciclosporin $^{44-46}$ or adalimumab ${ }^{49}$ and placebo $^{41,49}$ in moderate to severe plaque psoriasis. 
Table XXII. Summary, methotrexate (1-; B)

Recommended control parameters

Recommended dosage

Efficacy

Important contraindications

Important adverse reactions

Acute toxicity management

Important drug interactions (limited selection)

Level of evidence

Strength of recommendation

Other
Pregnancy testing (category $\mathrm{X}$ ), contraception use, full blood count, liver and renal function, chest X-ray, hepatitis serology, HIV

Liver biopsy is indicated in patients at risk for liver fibrosis (diabetes, overmass, history of liver problem, total dose $>1.5 \mathrm{~g}$ ) when methotrexate is used for prolonged periods as maintenance therapy

$5-25 \mathrm{mg} / \mathrm{wk}$

Effective for chronic moderate to severe plaque psoriasis

Lack of evidence in palmoplantar pustular psoriasis

May be effective in psoriatic arthritis

Alcohol use, impaired liver function, immunodeficiency, breastfeeding and pregnancy (both male and female patients considering pregnancy; category $\mathrm{X}$ )

Major toxic effects

Myelosuppression (often acute), hepatotoxicity, pneumonitis, gastro-intestinal ulceration and fetal abnormalities

Common side-effects include

Tiredness, nausea, anorexia, headache and alopecia

Leucovorin (folinic acid) rescue: $20 \mathrm{mg}$ folinic acid to be given parenterally

within 48 hours of last dose. Repeat 6-hourly parenterally or orally as tolerated until methotrexate levels below toxic range

Drugs increasing methotrexate toxicity, especially myelosuppression Sulphonamides, trimethoprim, phenytoin, barbiturates (increase antifolate

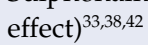

Salicylic acid, NSAIDs, probenicid, penicillin, ciclosporin (decrease metabolism, or renal excretion or displace protein binding $)^{33,38,42}$

Drugs increasing methotrexate toxicity, especially hepatotoxicity Ethanol, retinoids, NSAIDs ${ }^{33,38,42}$

1-

B

Consistent avoidance of alcohol

No blood donations are possible for the period of use
Both methotrexate $(0.5 \mathrm{mg} / \mathrm{kg} / \mathrm{wk})$ and ciclosporin (3 - 4 $\mathrm{mg} / \mathrm{kg} / \mathrm{d}$ ) were found to be effective in a study from India $(N=30)$, but methotrexate appeared to produce a more rapid and complete clearance. Side-effects were transient and minor. ${ }^{44}$ In contrast, there was no difference in efficacy, tolerability, rate of remission, time to remission or quality of life score in a study from the Netherlands $(N=88)$. Both methotrexate (15 $22.5 \mathrm{mg} / \mathrm{wk}$ given as 3 doses every 12 hours) and ciclosporin ( 3 $-5 \mathrm{mg} / \mathrm{kg} / \mathrm{d}$ ) over 16 weeks resulted in a reduction in psoriasis severity index from baseline of $\geq 75 \%$ (PASI $\geq 75$ ) in more than $60 \%$ of the patients. ${ }^{45}$ A study from Sweden $(N=68)$ showed a $58 \%$ reduction in PASI (PASI-75 $=24 \%$ ) for methotrexate (7.5 - $15 \mathrm{mg} /$ wk given as 3 doses every 12 hours with folate 5 $\mathrm{mg} / \mathrm{d}$ on non-treatment days), compared with a $72 \%$ reduction (PASI-75 $=58 \%$ ) for ciclosporin $(3-5 \mathrm{mg} / \mathrm{kg} / \mathrm{d}$ ) over 12 weeks. There was no difference in quality of life and side-effects were common but tolerable. Although both drugs were effective, ciclosporin was more effective in the short-term treatment of moderate to severe chronic plaque psoriasis. ${ }^{46}$

In an international randomised, double-blind, doubledummy, placebo-controlled study (Canadian and European cohort $N=271$ ), a patient response rate of PASI-75 was achieved in $79.6 \%$ of patients given adalimumab ( $80 \mathrm{mg}$ subcutaneously week 0 then $40 \mathrm{mg}$ every 2 weeks), $35.5 \%$ of those given methotrexate ( 7.5 - $25 \mathrm{mg}$ /week orally) and $18.9 \%$ of those receiving placebo for 16 weeks. All patients received $5 \mathrm{mg}$ folate weekly, 48 hours after oral medication (CHAMPION study).$^{49}$ Methotrexate dose, treatment duration and the use of folate could explain the different responses recorded above.
Placebo comparisons include the CHAMPION study ${ }^{49}$ and an RCT of methotrexate use for psoriatic arthritis. ${ }^{41}$ In 37 patients receiving methotrexate (7.5 - $15 \mathrm{mg} / \mathrm{wk}$ orally) or placebo for 12 weeks, a reduction in psoriasis surface area was noted for methotrexate compared with placebo.

The German guidelines ${ }^{33}$ had only 3 studies meeting inclusion criteria for monotherapy. They concluded that methotrexate as monotherapy was effective for moderate to severe plaque psoriasis despite the lack of definitive studies, but its use was limited by the controls needed during therapy and contraindications. It was not recommended for remission induction owing to its slow onset of action.

\section{Pustular psoriasis}

A systematic review of chronic palmoplantar pustulosis interventions found no trials for methotrexate. ${ }^{40}$

\section{Psoriatic arthropathy}

Although widely accepted as effective, methotrexate has been shown to be effective for psoriatic arthritis in only one study using high doses administered parenterally in a systematic review of psoriatic arthropathy interventions. There is inconclusive evidence for the use of low-dose oral methotrexate. $^{41}$

\section{Adverse effects}

Methotrexate use is associated with a large number of sideeffects and toxicity reactions. ${ }^{43}$ Excretion is via the kidney and drug levels are therefore affected by renal function (Table XXII). 


\section{Folic acid supplementation}

The use of folate supplementation to reduce side-effects is controversial. A systematic review of its use in rheumatoid arthritis (RA) could not show any benefit owing to lack of uniformity of outcome measures, but did support the protective effects of folate for gastro-intestinal tract (GIT) and mucosal side-effect reduction. The dose of folic acid or folinic acid did not appear to matter. ${ }^{50} \mathrm{~A}$ recent randomised placebo-controlled study in RA patients $(N=454)$ showed folate supplementation to be protective for hepatotoxicity

\section{Therapeutic recommendation}

- Methotrexate is effective for chronic moderate to severe plaque psoriasis.

- Methotrexate has been shown to:

- Be effective for moderate to severe plaque psoriasis when used at doses of $7.5-25 \mathrm{mg} / \mathrm{wk}$

- Have equivalent but varying efficacy compared with ciclosporin, dependent on the population and dose studied and the use of folate supplementation

- Not be as effective as adalimumab and to cause more adverse events.

- There are no trials of methotrexate efficacy for palmoplantar pustular psoriasis.

- Methotrexate may be effective for psoriatic arthritis.

- Methotrexate use is limited by the side-effect and contraindication profile and monitoring required while on use.

- Folate supplementation may reduce hepatotoxicity side-effects in psoriatic patients, but can compromise methotrexate efficacy. compared with placebo, but it had no effect on GIT or mucosal symptoms. ${ }^{51}$ Folate supplementation has been shown to compromise methotrexate efficacy. ${ }^{52,53}$ Concomitant use of folate increased the total dose of methotrexate necessary to achieve the same response when compared with methotrexate alone. ${ }^{51,53}$

\subsection{Alternative systemic therapies}

Alternative systemic agents sometimes used for recalcitrant psoriasis management include hydroxyurea, sulfasalazine, azathioprine, mycophenolate mofetil, fumaric acid esters, 6-thioguanine and leflunomide. Only those that are available in South Africa for which there is supportive published evidence of efficacy from RCTs are included.

\subsubsection{Hydroxyurea/hydroxycarbamide (Table XXIII)}

\section{Background}

Hydroxyurea (Hydrea ${ }^{\circledR}$ ) is cytotoxic, inhibiting DNA synthesis. Its mechanism of action is unknown in psoriasis. It suppresses the bone marrow and is best regarded as teratogenic, but is not nephrotoxic or significantly hepatotoxic. ${ }^{54,55}$

Hydroxyurea has been proposed as a treatment for HIV because it inhibits DNA synthesis and causes cell cycle arrest and has favourable toxicity and drug interaction profiles. Laboratory work has shown that it blocks HIV transcription and/or replication and acts synergistically with didanosine in this regard. ${ }^{56}$

\section{Evidence of efficacy}

Plaque psoriasis

A systematic review ${ }^{36}$ reported one small RCT in which hydroxyurea ( $0.5 \mathrm{~g}$ twice daily) was compared with placebo in 10 patients with severe psoriasis in a $2 \times 4$-week cross-over

Table XXIII. Summary, hydroxyurea [1-; C]

Recommended control parameters

Recommended dosage

Response rate

Efficacy

Important adverse reactions

Acute toxicity

Important drug interactions Level of evidence

Strength of recommendation
Pregnancy testing (category X), contraception use, full blood count, liver and renal functions, malignancies

$0.5-1 \mathrm{mg} / \mathrm{d}$ for recalcitrant psoriasis

$>60 \%$ achieve $60-80 \%$ clearance, $^{54,55}$ open-label case series

PASI-75 in 53\%; PASI-90 in 16\% (open-label study) ${ }^{57}$

Effective for recalcitrant psoriasis

Lack of published evidence to support efficacy of hydroxyurea for palmoplantar psoriasis

Lack of published evidence to support efficacy of hydroxyurea for psoriatic arthritis

May have a role in the treatment of HIV-affected patients

Use is associated with bone marrow suppression and the side-effects may develop months after starting treatment ${ }^{54,55}$

Macrocytosis is common and not necessarily associated with anaemia may be seen within 24 hours of the first dose and is a good indicator of compliance $^{55,57}$

Mucocutaneous side-effects: alopecia, skin, hair and nail discoloration, painful lower leg ulceration, dermatomysitis and drug-induced lupus (longterm use $)^{54,55}$

There is a risk of malignancies (cutaneous, leukaemia transformation) ${ }^{54,55}$ Acute mucocutaneous toxicity causes intense acral erythema and oedema, generalised pigmentation and stomatitis ${ }^{54,55,57}$

Predominantly drugs causing myelosuppression $1-$

C 
study. Improvement was noted by both patients and doctors during periods of active therapy $(9 / 10)$ compared with placebo $(1 / 10)$.

A review of the use of hydroxyurea for psoriasis ${ }^{55}$ identified a preliminary report of a small RCT comparing hydroxyurea (1 $\mathrm{g} / \mathrm{d})$ with methotrexate $(2.5 \mathrm{mg} / \mathrm{d})$ in 8 patients in a $2 \times 6$-week cross-over study. Hydroxyurea was reported to be as effective as, or better than, methotrexate in $5 / 8$ patients.

Two open-label case series summarised in the British Association of Dermatology guidelines ${ }^{54}$ and the above review $^{55}$ reported that $>60 \%$ of the 60 and 85 patients treated with hydroxyurea, respectively, achieved a good or excellent response (38/60 achieved $60-80 \%$ clearance, 10/60 no response; $51 / 85$ clear or almost clear, $6 / 80$ no response). Doses of hydroxyurea and treatment period varied $(1 \mathrm{~g} / \mathrm{d}$ over 4 12 weeks, repeated over 18 months; $0.5 \mathrm{~g} / \mathrm{d}$ increased to 1.5 $\mathrm{g} / \mathrm{d}$ in poor responders over 4 - 36 months). Responses were seen within the first 6 weeks of therapy and the response was maintained on therapy. Remission was seen for all forms of psoriasis including pustular and erythrodermic psoriasis. Additional case series were identified in the review. ${ }^{55} \mathrm{In}$ 100 patients managed with hydroxyurea $(1 \mathrm{~g} / \mathrm{d}$ treated for variable periods over 8 years) a 'worthwhile' response was seen in 63/100 patients including the 18 'excellent' responses. Two smaller series (20 and 16 patients) reported similar good response rates.

An open-label study of 31 chronic plaque psoriasis patients in India reported a good, but slow, response for hydroxyurea dosed at $1.0 \mathrm{~g}-1.5 \mathrm{~g} / \mathrm{d}$. Treatment duration ranged from 6 to 136 weeks. Good responses (70 - 90\% reduction in PASI) were reported for $17 / 31$ (53\%) with complete or almost complete $(>90 \%$ reduction in PASI) responses seen in $8 / 31$

(16\%). Macrocytosis was seen in all patients by 2 weeks and all adverse effects were reported as mild and reversible. ${ }^{57}$

The German guidelines did not include hydroxyurea. ${ }^{33}$

\section{Pustular psoriasis}

A systematic review of chronic palmoplantar pustulosis interventions found 1 small (13 patients), short, cross-over trial comparing hydroxyurea with placebo. There were no differences in the scores during the placebo and intervention period. ${ }^{40}$

\section{Therapeutic recommendation}

- Hydroxyurea has been shown to be effective as a systemic agent at doses of $0.5-1.5 \mathrm{~g} / \mathrm{d}$ for recalcitrant psoriasis.

- There is a lack of evidence to support efficacy of hydroxyurea for palmoplantar pustular psoriasis.

- There are no trials of hydroxyurea use for psoriatic psoriasis.

- Hydroxyurea may have a role in treating HIV-affected patients.

- Macrocytosis is commonly seen and a marker of compliance.
Psoriatic arthropathy

A systematic review of chronic psoriatic arthritis interventions found no trials for hydroxyurea efficacy that could be evaluated. ${ }^{41}$

\section{Adverse effects}

Adverse effects of hydroxyurea are set out in Table XXIII.

\subsubsection{Sulfasalazine (Table XXIV)}

\section{Background}

Sulfasalazine (Salazopyrin ${ }^{\circledR}$ ) is an anti-inflammatory agent used widely for treating inflammatory joint disease. It is split by intestinal bacteria into sulfapyridine and 5-aminosalicylic acid. Sulfapyridine is absorbed, metabolised in the liver and excreted in the kidney. The 5-aminosalicylic acid is excreted in the faeces. Its mechanism of action is unknown in psoriasis. It is potentially a bone marrow suppressant. ${ }^{36}$

\section{Evidence of efficacy}

Plaque psoriasis

A systematic review ${ }^{36}$ revealed one small RCT in which sulfasalazine ( $3-4 \mathrm{~g} / \mathrm{d}$ ) was compared with placebo in 50 patients with plaque psoriasis over 8 weeks. Improvement $(>60 \%)$ was noted in $7 / 17$ (41\%) of those treated who were assessable, compared with none of those receiving placebo $(0 / 27)$. Six of the original 23 patients withdrew because of sideeffects.

The British Association of Dermatologists ${ }^{53}$ and German guidelines $^{33}$ did not include sulfasalazine.

\section{Pustular psoriasis}

A systematic review of chronic palmoplantar pustulosis interventions did not report any studies for sulfasalazine use. ${ }^{40}$

\section{Psoriatic arthropathy}

A systematic review of chronic psoriatic arthritis interventions found 6 trials evaluating sulfasalazine efficacy meeting their criteria for inclusion. ${ }^{41}$ They conclude that there is good published efficacy for sulfasalazine use for treating psoriatic arthritis, despite a significant placebo response for the condition.

\section{Adverse effects}

Adverse effects are set out in Table XXIV.

\section{Therapeutic recommendation}

- There is little evidence to support the efficacy of sulfasalazine for psoriasis of the skin.

- Sulfasalazine may have a role in treating psoriasis patients with psoriatic arthritis.

\subsection{Biologicals}

\subsubsection{Overview and background information}

Although effective, the conventional systemic drugs including methotrexate, ciclosporin and retinoids are associated with considerable toxicity that limits their long-term use. Recent developments in more targeted therapies involving biological 


\begin{tabular}{|c|c|}
\hline Recommended control parameters & $\begin{array}{l}\text { Pregnancy testing (category B risk), contraception use, full blood count, liver } \\
\text { and renal function }\end{array}$ \\
\hline Efficacy & $\begin{array}{l}\text { Minimal published evidence to support sulfasalazine efficacy at doses of } 3 \text { - } 4 \\
\mathrm{~g} / \mathrm{d} \text { for chronic plaque psoriasis in those who can tolerate it } \\
\text { Lack of published evidence to support efficacy of sulfasalazine for } \\
\text { palmoplantar pustular psoriasis } \\
\text { Well-documented published evidence that sulfasalazine is effective for } \\
\text { psoriatic arthritis }\end{array}$ \\
\hline Important adverse reactions & $\begin{array}{l}\text { Sulfasalazine is not well tolerated owing to associated gastro-intestinal side- } \\
\text { effects and headache } \\
\text { Reversible oligospermia and infertility are relatively common } \\
\text { Hepatotoxicity, haematological (binds iron, precipitates folate deficiency) and } \\
\text { hypersensitivity reactions are described }{ }^{36}\end{array}$ \\
\hline Important drug interactions & $\begin{array}{l}\text { Potentiates the action of drugs metabolised by the cytochrome P450 enzyme } \\
\text { system }\end{array}$ \\
\hline Level of evidence & 2 \\
\hline Strength of recommendation & C \\
\hline
\end{tabular}

agents, such as anti-T-cell agents and inhibitors of tumour necrosis factor-alpha (TNF- $\alpha$ ), offer an alternative treatment approach with the possibility of longer continuous therapy, which may translate into disease control and improved quality of life.

Biological agents are proteins that can be extracted from animal tissue or produced by recombinant DNA technology and possess pharmacological activity. ${ }^{58}$ Biological therapies block specific molecular steps in the pathogenesis of psoriasis. Three types of molecules have been studied for use in psoriasis:

- recombinant human cytokines or growth factors

- monoclonal antibodies

- fusion proteins.

The nomenclature of biologicals has been standardised, and the suffix of the drug name helps with identification (Table $X X V)$.

\subsubsection{Strategies for biological therapy in psoriasis}

Biologicals used to treat psoriasis target two key steps in the pathogenesis of the disease, namely either:

- T-cell or antigen-presenting cell targeted (e.g. efaluzimab, alefacept), or

- acting on TNF- $\alpha$ (e.g. adalumimab, etanercept, infliximab).

\subsubsection{Considerations for biological therapy}

In considering a patient for biological therapy, the following assessment tools are used:

- PASI $^{59}$

- DLQI ${ }^{58}$

- BSA affected. ${ }^{60}$

The BSA is used where PASI is not applicable, e.g. in pustular psoriasis.

\section{Eligibility criteria}

To be considered for treatment, patients:

- must have severe disease, and

- must fulfil one of the clinical categories outlined in (ii) below.

(i) Definition of severe disease:

- PASI score $\geq 10$

- or BSA of $\geq 10 \%$ if PASI is not applicable

- disease should be severe for more than 6 months

- disease should be resistant to therapy

- patient should be a candidate for systemic therapy.

In some circumstances, e.g. disabling acral disease, patients may fall outside this definition but may still be considered for treatment.

(ii) At least one of the following clinical categories must be fulfilled.

Patients who:

- have developed or are at higher than average risk of developing clinically important drug-related toxicity and where alternative standard therapy cannot be used

- are or have become intolerant to or cannot receive standard systemic therapy

- are or have become unresponsive to standard therapy

- have disease that is only controlled by repeated inpatient management

- have significant, co-existent, unrelated co-morbidity that precludes use of systemic agents such as ciclosporin or methotrexate

- have severe, unstable, life-threatening disease (erythroderma or pustular psoriasis)

\section{Table XXV. Nomenclature of the biologicals}

\begin{tabular}{ll}
\hline -ximab & Chimeric monoclonal antibody (infliximab, rituximab, etc.) \\
-zumab & Humanised monoclonal antibody (efalizumab, etc.) \\
-umab & Human monoclonal antibody (adalimumab, etc.) \\
-cept & Receptor-antibody fusion protein (alefacept, etanercept, onercept, etc.)
\end{tabular}


- have psoriatic arthritis fulfilling the South African Rheumatology Society eligibility criteria for treatment with anti-TNF agents in association with skin disease.

Standard systemic therapy includes:

- acitretin

- ciclosporin

- methotrexate

- narrow-band ultraviolet (UV) B

- PUVA.

Unresponsive to standard therapy is defined as an unsatisfactory clinical response (less than 50\% improvement in baseline PASI score or percentage BSA where PASI is not applicable, and less than 5-point improvement in DLQI) to at least 3 months of treatment in the therapeutic dose range to the following treatments:

- methotrexate single weekly dose (oral, subcutaneous, intramuscular) $15 \mathrm{mg}$, max. 25 - $30 \mathrm{mg}$

- acitretin $25-50 \mathrm{mg} / \mathrm{d}$

- ciclosporin $2.5-5 \mathrm{mg} / \mathrm{kg} / \mathrm{d}$

- narrow-band UVB or PUVA (non-response, rapid relapse or exceeding recommended maximum doses) 150 - 200 treatments for PUVA and 350 treatments for narrow-band $\mathrm{UVB}^{61}$

A DLQI score of $>10$ correlates with a substantial effect on the patient's quality of life.

\section{Exclusion criteria for anti-TNF agents and efalizumab}

- Pregnant or breastfeeding.

- Active infections. High risk includes the following:

- chronic leg ulcers
- persistent or recurrent chest infections

- indwelling urinary catheter

- latent tuberculosis.*

- Malignancy or premalignancy states excluding:

- adequately treated non-melanoma skin cancer

- malignancies diagnosed and treated more than 10 years previously.

- Demyelinating disease.*

- Congestive cardiac failure.*

Relative contraindications

- PUVA therapy >200 treatments, especially when followed by ciclosporin therapy

- HIV positive or AIDS

- hepatitis B or C.

\section{Adequate response to treatment}

This is defined as a $50 \%$ or greater reduction in baseline PASI score (or percentage BSA where PASI is not applicable) and a 5-point or greater improvement in DLQI within 3 months of initiation of treatment.

\section{Withdrawal of therapy}

Therapy should be withdrawn if the criteria for adequate response have not been fulfilled in 3 months.

\section{Who should prescribe biological therapy?}

Treatment should be initiated and monitored (Table XXVI) by consultant dermatologists experienced in managing difficult psoriasis.

*These apply to anti-TNF agents only.

Table XXVI. Recommended pretreatment and monitoring investigations

\begin{tabular}{|c|c|c|c|}
\hline & & Pretreatment & Monitoring \\
\hline \multicolumn{4}{|l|}{ Disease severity assessment } \\
\hline \multicolumn{4}{|l|}{ Skin } \\
\hline PASI & & Yes & 3 months, then every 6 months \\
\hline DLQI & & Yes & 3 months, then every 6 months \\
\hline $\begin{array}{l}\text { Joints - follow recommendations of } \\
\text { SA Rheumatological Association }\end{array}$ & & Yes & 3 months, then every 6 months \\
\hline \multicolumn{4}{|l|}{$\begin{array}{l}\text { General health (symptom enquiry and } \\
\text { clinical examination) }\end{array}$} \\
\hline Infection & & Yes & 3 - 6-month intervals \\
\hline Demyelination & & Yes & 3 - 6-month intervals \\
\hline Heart failure & & Yes & 3 - 6-month intervals \\
\hline Malignancy (including skin) & & Yes & 3 - 6-month intervals \\
\hline \multicolumn{4}{|l|}{ Assessment for latent tuberculosis (Fig. 2) } \\
\hline \multicolumn{4}{|l|}{ Blood tests } \\
\hline $\mathrm{FBC}$ & & Yes & $\begin{array}{l}\text { Efalizumab: monthly for first } 3 \\
\text { months, then every } 3 \text { months, anti- } \\
\text { TNF agents: } 3 \text { months, then every } 6 \\
\text { months }\end{array}$ \\
\hline $\mathrm{U}+\mathrm{E}$, creatinine & & Yes & 3 months, then every 6 months \\
\hline LFT & & Yes & 3 months, then every 6 months \\
\hline Hepatitis B and C & & Yes & - \\
\hline HIV & & Consider in patients at risk & - \\
\hline $\begin{array}{l}\text { Auto-antibodies (antinuclear antibodies, } \\
\text { antidouble-stranded DNA antibodies) }\end{array}$ & & Yes & - \\
\hline Urine & Urinalysis & Yes & 3 months, then every 6 months \\
\hline Radiology & CXR & Yes & - \\
\hline
\end{tabular}




\section{GUIDELINE}

Group 1

Abnormal CXR suggestive of TB or previous history of TB treatment
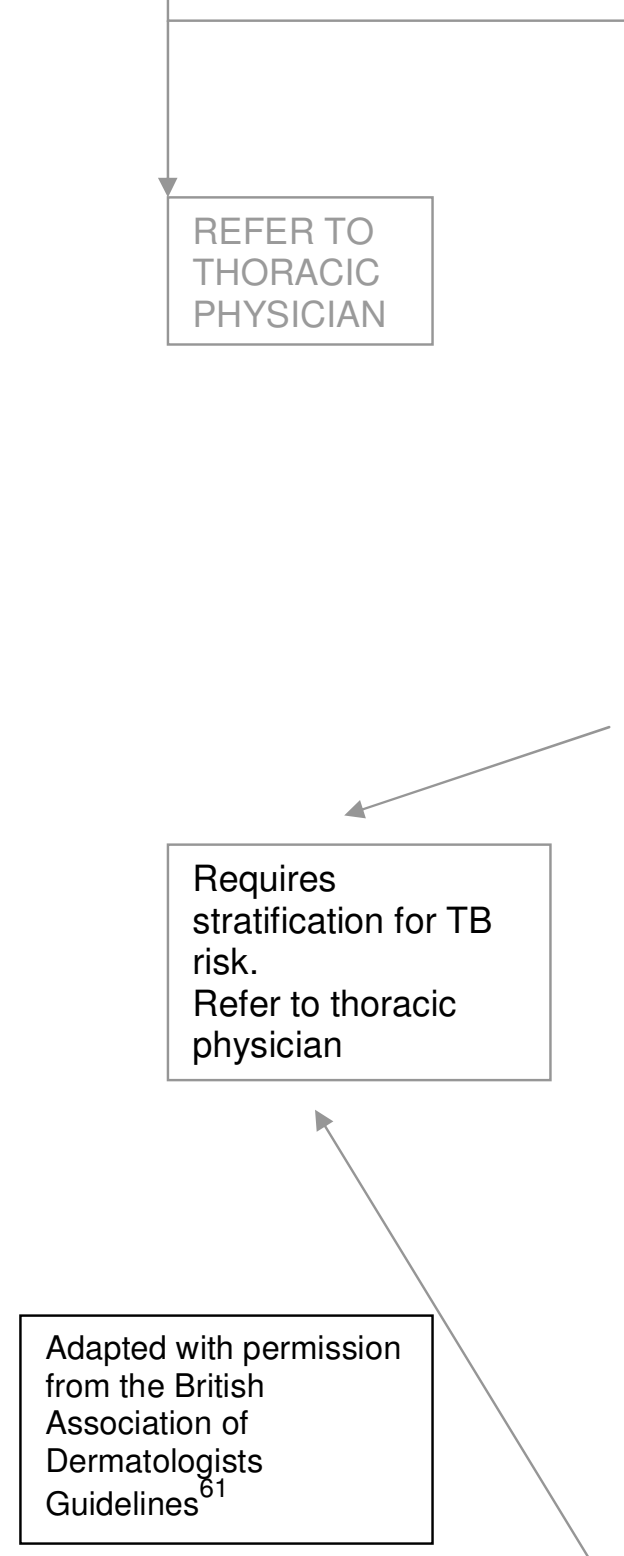

Fig. 2. Algorithm for assessment and management of tuberculosis (TB) in patients scheduled for anti-TNF therapy. ${ }^{62}$

\section{Comment:}

Tuberculin skin testing may be unreliable in patients who are immunocompromised. after cessation.

A new diagnostic test that assays interferon-gamma to identify TB is not any better than the Mantoux test as neither is capable of differentiating between latent and active disease. ${ }^{95}$
Group 2

Normal CXR and no history of prior TB

On oral immunosuppressive therapy

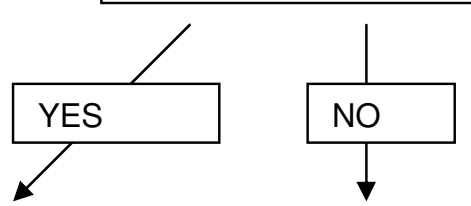

Tuberculin test invalid.

Assess risk

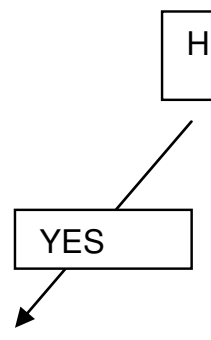

Had BCG?
Tuberculin test (Mantoux or Heaf)
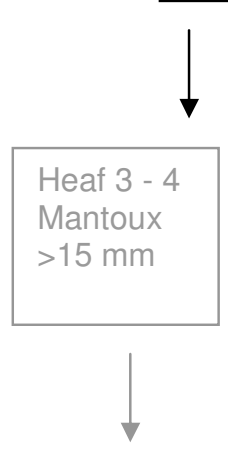

Requires

stratification

for TB risk
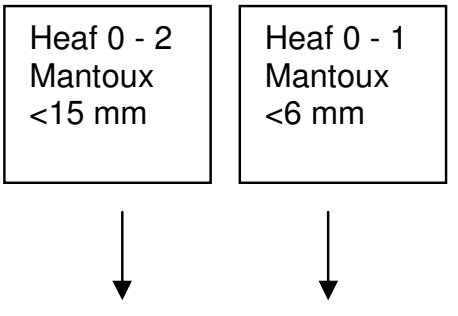

No further action
Tuberculin test

(Mantoux or Heaf)
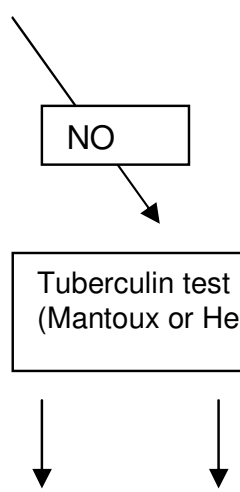

Heaf 2 - 4

Mantoux

$\leq 6 \mathrm{~mm}$

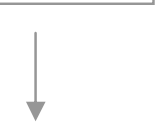

Requires

stratification

for TB risk

Clinical awareness of the possibility of TB should be maintained throughout anti-TNF therapy and for 6 months 
For the purposes of this section of the guideline, products are listed in their therapeutic class and in subsequent alphabetical order.

\subsubsection{T-cell-targeted biologicals}

\subsubsection{Alefacept}

Alefacept (Amevive ${ }^{\circledR}$; Biogen) was the first biological agent approved for treatment of psoriasis. Alefacept is a recombinant dimeric fusion protein. It binds to CD2 on the memory-effector $T$ lymphocytes. The dose regimen, precautions and clinical response are summarised in Table XXVII.

\section{General assessment}

The efficacy of alefacept as induction therapy has been demonstrated in placebo-controlled studies, with $28 \%$ of patients achieving PASI-75 after a 12-week course $(7.5 \mathrm{mg}$ administered intravenously once weekly), rising to $40 \%$ in those patients receiving a second treatment course. ${ }^{63}$ Intramuscular alefacept (10 or $15 \mathrm{mg}$ once weekly) demonstrated PASI-75 in 28 - 33\% of patients after 12 weeks. Data for longer treatment with alefacept are based on reports of repeated 12-week treatment courses.$^{63}$ Follow-up data from both phase III studies showed that after one course of therapy, $29 \%$ of patients achieved PASI-75. Among patients who received at least two courses of alefacept, an incremental response was seen with $54 \%$ achieving PASI-75. ${ }^{63}$ For patients who responded, remission lasted an average of 7 months. Continuous treatment is not prescribed in clinical practice; rather, alefacept is given as intermittent 12 -week treatment courses, either as monotherapy or in combination with other agents. ${ }^{63}$

Alefacept is generally well tolerated. Chills are occasionally experienced, particularly with IV administration and usually soon after dosing, and are often limited to one or two occasions during early treatment. It is necessary to monitor CD4+ cell counts before and during alefacept therapy, ${ }^{63}$ and the drug should be withheld if the CD4 count drops below 250 cells $/ \mu$ and discontinued if it remains below 250 cells $/ \mu l$ for 4 consecutive weeks. ${ }^{64}$ However, randomised controlled studies do not reveal a higher incidence of infections and opportunistic infections. The rate of malignancies was similar to the control group. ${ }^{65}$

\subsubsection{Efalizumab}

A press release dated 19 February 2009 released by the European Medicines agency reads as follows:

'The European Medicines Agency (EMEA) has recommended the suspension of the marketing authorisation for Raptiva (efalizumab), from Serono. The EMEA's Committee for Medicinal Products for Human Use (CHMP) has concluded that the benefits of Raptiva ${ }^{\circledR}$ no longer outweigh its risks, because of safety concerns, including the occurrence of progressive multifocal leukoencephalopathy $(P M L)$ in patients taking the medicine.' The FDA has withdrawn the drug since June $2009 .{ }^{67}$

\subsubsection{Cytokine modulators: TNF- $\alpha$ blockers}

\subsubsection{Adalimumab}

Adalimumab (Humira ${ }^{\circledR}$, Abbott Laboratories) is the first antiTNF- $\alpha$ antibody that is entirely human in origin. In theory, antibody formation is less likely to occur. It is administered subcutaneously at a dose of $40 \mathrm{mg}$ fortnightly, although it can be administered weekly, with or without methotrexate. The dosage regimen, precautions and clinical response are summarised in Table XXVIII.

In the UK adalimumab was licensed for the treatment of RA in September 2003. It is registered in South Africa for the treatment of psoriasis and psoriatic arthritis, and is also licensed for the treatment of other inflammatory conditions such as Crohn's disease, RA and ankylosing spondylitis. ${ }^{68}$

Early evidence indicated that PASI-75 can be achieved in $53 \%$ of patients after 12 weeks' treatment. More recent evidence shows that PASI-75 can be achieved in $71 \%$ of patients by 16 weeks. $^{69}$

Recent published data, the first head-to-head trial evaluating the comparative efficacy of biological versus conventional systemic treatment for psoriasis, demonstrated significantly higher efficacy of adalimumab compared with methotrexate; $80 \%$ of patients receiving adalimumab and $36 \%$ of patients receiving methotrexate achieved PASI-75 after 16 weeks. ${ }^{63}$

Data for the treatment of RA suggest that adalimumab is as efficacious as infliximab or etanercept, but no head-to-head trials have been conducted..$^{70}$

Compared with other biological agents, longer-term efficacy data for adalimumab are more limited. In the larger phase

\section{Table XXVII. Summary, alefacept (1; A)}

Recommended dose

Monitoring

Side-effects

Expected beginning of clinical effect

Clinical response
Level of evidence

Strength of recommendation

Other
$15 \mathrm{mg}$ IM (7.5 mg IV) weekly for 12 weeks

CD4 T-cell count before treatment and weekly during treatment

Some patients experience chills with the first injections

Slow onset of action with apparent clinical improvement after 6 - 8 weeks PASI-75 after 12 or 24 weeks achieved by $14 \%$ and $28 \%$ of patients and respectively in $40 \%$ after a 2 nd course. ${ }^{65,66}$ Often sustained remission. Prior response to alefacept is a likely marker of future treatment response; patients responding to the first course of therapy may therefore be treated long term with repeated 12 -week courses of alefacept at a minimum of 24 -week intervals ${ }^{13}$

Improved outcome with second course of treatment and consistent benefit of repeated administration ${ }^{13}$

$1^{13}$

$\mathrm{A}^{13}$

In phase II trials for psoriatic arthritis 
Table XXVIII. Summary, adalimumab (1; A)

Recommended dose

Monitoring

Side-effects

Expected beginning of clinical effect

Clinical response

Level of evidence

Strength of recommendation

Other
$80 \mathrm{mg}$ in the first week, $40 \mathrm{mg}$ in the second week, followed by $40 \mathrm{mg}$ every other week, given subcutaneously

Infection screen prior to treatment (NB: active or latent TB must be excluded)

Injection site reactions common

Rapid onset of action ${ }^{69}$

PASI-75 at 16 weeks achieved by $71 \%{ }^{69} 64 \%$ by 60 weeks ${ }^{13}$

Rebound typically does not occur, but clearance better maintained with continuous use $^{13}$

$1^{13}$

$\mathrm{A}^{13}$

Approved for the treatment of psoriatic arthritis and psoriasis
III study, among patients reaching PASI-75 after treatment with adalimumab, a loss of response was observed following re-randomisation to placebo, suggesting that continuous treatment is necessary to maintain a response. ${ }^{69}$ In this study, after 24 weeks of continuous treatment, $70 \%$ of patients achieved PASI-75, and at 33 weeks $89 \%$ achieved this response. However, PASI scores for longer treatment duration were not reported.

In an open-label extension to the initial phase II study, in which 106 patients received continued treatment for 60 weeks, PASI-75 was achieved by $64 \%$ of patients receiving continuous weekly dosing and by $56 \%$ receiving adalimumab every other week. ${ }^{70}$

Safety data for adalimumab in psoriasis are also limited compared with other biological agents. The most commonly reported adverse events in patients treated with adalimumab were nasopharyngitis, upper respiratory tract infection and headache. However, the incidence of severe adverse events was low and comparable in the adalimumab and placebo treatment groups. Until more data are available, the caveats for use of adalimumab should be considered to be the same as those for other TNF- $\alpha$ blockers. ${ }^{63}$

\subsubsection{Etanercept}

Etanercept (Enbrel ${ }^{\circledR}$, Wyeth Pharmaceuticals) is a fully human soluble recombinant p75 TNF receptor that blocks the binding of TNF to cell surface receptors, thereby neutralising its biological activity.

The dose regimen, precautions and clinical response are summarised in Table XXIX.

\section{General assessment}

Etanercept is registered in South Africa for the treatment of psoriasis and psoriatic arthritis. It is also licensed for the treatment of other inflammatory conditions such as RA, juvenile chronic arthritis and ankylosing spondylitis. ${ }^{71}$

The recommended dose of etanercept for the treatment of psoriasis is $25 \mathrm{mg}$ subcutaneously twice weekly by selfadministration, although this may be increased to $50 \mathrm{mg}$ twice weekly. Etanercept may be given for up to 24 weeks.

PASI-75 was achieved in up to $34 \%$ of patients after 12 weeks of treatment with $25 \mathrm{mg}$ subcutaneous etanercept twice weekly. Continuing treatment for 24 weeks further increased response. Doubling the dose to $50 \mathrm{mg}$ twice weekly achieved PASI-75 in up to $49 \%$ of patients at 12 weeks. ${ }^{72,73}$ The median time to relapse after cessation of treatment was approximately 3 months, with no rebound observed.

Etanercept treatment response has been found to be dose dependent, with a greater proportion of patients achieving PASI-75 with the $50 \mathrm{mg}$ twice-weekly dosing regimen than with the $25 \mathrm{mg}$ twice-weekly regimen over 12 weeks. Extending treatment to 24 weeks also improves response, with $44-45 \%$ of patients achieving PASI-75 with the $25 \mathrm{mg}$ twice-weekly regimen, and 59\% with the $50 \mathrm{mg}$ twice-weekly regimen. ${ }^{63}$

Longer-term data for up to 60 weeks of etanercept treatment have been reported in an open-label extension study of a phase III trial with treatment non-responders. At week 36, among 145 patients, $12 \%$ had achieved PASI-75. At week $60(N=112), 23 \%$ had achieved PASI-75. Another long-term, open-label extension study using etanercept $50 \mathrm{mg}$ per week reported that, after initial efficacy at 12 weeks, $63 \%$ of patients who continued treatment reached PASI-75 at week 48 . However, a modest reduction in response was seen with longer-term treatment, and at 96 weeks a PASI-75 response was seen in only 51\% of patients. ${ }^{63}$

Table XXIX. Summary, etanercept (1; A)

Recommended dose

Monitoring

Side-effects

Expected beginning of clinical effect

Clinical response

Level of evidence

Strength of recommendation

Other
25 - $50 \mathrm{mg}$ subcutaneously twice weekly for an indefinite period

Infection screen prior to treatment (NB: active or latent TB must be excluded)

Injection site reactions common

Rapid onset within 2 - 3 weeks

PASI-75 at 12 weeks achieved by 34\% (25 mg)/49\% (50 mg), ;2,73 PASI-75 at 24 weeks $45 \%$ (25 mg) and 59\% (50 mg); PASI-75 at 60 weeks achieved by $23 \%{ }^{13,72,73,75}$

Median time to relapse 3 months; relapse rates are variable $1^{13}$

$\mathrm{A}^{13}$

Approved for the treatment of psoriatic arthritis 
Etanercept has been used in children aged 4 - 17 years with plaque psoriasis. Doses of $0.8 \mathrm{mg} / \mathrm{kg}$ to a maximum of $50 \mathrm{mg}$ were given once weekly, and 57\% achieved PASI-75 compared with $11 \%$ of those on placebo. ${ }^{74}$

Etanercept has been well tolerated in clinical trials, apart from mild injection site reactions occurring in up to $36 \%$ of patients; these rarely led to discontinuation of treatment. ${ }^{75}$ Neutralising antibody formation could not be observed. There are concerns about increased infection rates and a risk of malignancy associated with the use of etanercept. However, a safety review in RA showed a similar rate of serious infections for etanercept- and placebo-treated patients. No opportunistic infections were observed and the incidence of malignancies was similar to that expected. ${ }^{76}$

\subsubsection{Infliximab}

Infliximab (Revellex ${ }^{\circledR}$ in South Africa/Remicade ${ }^{\circledR}$ internationally; Schering-Plough) is a monoclonal mouse/ human chimeric antibody that binds to TNF- $\alpha$, thereby neutralising its activity. The dosage regimen, precautions and clinical response are summarised in Table XXX.

\section{General assessment}

Infliximab is registered in South Africa for the treatment of psoriasis and psoriatic arthritis. It is also licensed for the treatment of other inflammatory conditions such as Crohn's disease in adults and children, ulcerative colitis, RA and ankylosing spondylitis. ${ }^{77}$

The efficacy of infliximab in psoriasis has been demonstrated in two phase II studies and a subsequent larger phase III study (EXPRESS study), involving a total of 660 patients, which found that treatment with infliximab (administered intravenously in doses of 3,5 or $10 \mathrm{mg}$ at weeks 0,2 and 6) resulted in achievement of PASI-75 after 10 weeks in $70-80 \%$ of patients. Rapid clinical improvements were observed in all three studies. ${ }^{63,78}$

Longer-term data from the EXPRESS study have been reported, with treatment continued (as an intravenous infusion of $5 \mathrm{mg} / \mathrm{kg}$ ) at weeks 0,2 and 6 , and then every 8 weeks through to week 46 . Of 271 patients receiving continued infliximab, a sustained response was observed at week 24, with $82 \%$ of patients attaining PASI-75, after which a moderate reduction in efficacy was noted, falling to $61 \%$ of patients reaching PASI-75 at week $50 .{ }^{63}$
Similar findings were reported in a more recent comparison of continuous and intermittent infliximab therapy over 1 year, which involved an initial 835 patients. ${ }^{33}$ In an initial placebocontrolled induction phase of this study, in the active treatment arm (intravenous infusions of 3 or $5 \mathrm{mg} / \mathrm{kg}$ ) at weeks 0,2 and 6, PASI-75 was achieved in 70\% (3 mg/ kg) and 75\% (5 mg/ $\mathrm{kg})$ of patients. ${ }^{63}$

Patients were then randomised to receive continuous treatment (as intravenous infusions every 8 weeks) or intermittent 'as-needed' dosing (given when a PASI-75 response was lost). With continuous therapy up to week 26 , PASI-75 scores were maintained in $64 \%(3 \mathrm{mg} / \mathrm{kg})$ and $78 \%$ $(5 \mathrm{mg} / \mathrm{kg}$ ) of patients. Subsequently, a reduced response to continuous 8-weekly infusion therapy was observed, with PASI-75 achieved by $44 \%$ of patients $(3 \mathrm{mg} / \mathrm{kg}$ ) and $54 \%$ of patients $(5 \mathrm{mg} / \mathrm{kg})$ at week 50 . Patients receiving continuous dosing had consistently higher PASI-75 scores than those treated with intermittent dosing, and PASI scores were greater with the higher dose of infliximab. ${ }^{63}$

These data suggest that infliximab is effective as continuous treatment for up to 1 year, with some loss of response over time. Its benefits beyond this time frame are not known owing to the lack of longer-term data. ${ }^{63}$

Infliximab has been well tolerated in clinical trials, with safety data available from over 1 million patients treated with the drug for various inflammatory conditions. ${ }^{79}$

More commonly observed adverse events include headaches, nausea, upper respiratory infections and infusion reactions. Infusion reactions occurred in up to $16 \%$ of patients, but only $2 \%$ discontinued the treatment because of the reactions. ${ }^{80}$ There have been reports of new or worsening congestive cardiac failure in patients treated with infliximab and it should therefore be used with caution in patients with pre-existing cardiac failure. ${ }^{81}$ In a small number of patients with Crohn's disease or RA, infections, antinuclear antibody formation and drug-induced auto-immune disease have been reported. ${ }^{82,83}$ Patient-years of infliximab usage are associated with more reports of opportunistic infections, including tuberculosis, than other anti-TNF agents. There have also been rare reports of demyelinating disease ${ }^{84}$ All patients considered for treatment with infliximab should be screened for active infection, in particular tuberculosis. There is currently no indication of higher rates of malignancy in patients treated with infliximab, but long-term data are not yet available. There

\section{Table XXX. Summary, infliximab (1; A)}

Recommended dose

Monitoring

Side-effects

Expected beginning of clinical effect Clinical response

Level of evidence

Strength of recommendation

Other
$5 \mathrm{mg} / \mathrm{kg}$ IV (over 2 - 3 hours) at 0,2 and 6 weeks (RA dose regimen)

Infection screen prior to treatment (NB: active or latent TB must be excluded)

Infusion reactions are common

Increased risk of infection, caution in congestive cardiac failure, demyelinating disorders

Risk of antibody formation

Rapid onset, within 1 week

PASI-75 at 10 weeks achieved by $>82 \% ; 61 \%$ of patients achieved PASI-75 at week $50^{13,63,78}$

$1^{13}$

$\mathrm{A}^{13}$

Effective for psoriatic arthritis 
is concern about an increased risk of lymphoma, particularly in patients with RA, who appear to be more susceptible. ${ }^{80}$ In patients with psoriasis who receive TNF- $\alpha$ blockers, long-term pharmacovigilance is required for skin cancer, as a significant number of these patients with severe disease will have also received photochemotherapy (PUVA).

\subsubsection{Other cytokine modulators}

\subsubsection{IL-12/23 monoclonal antibody (Ustekinumab)}

Ustekinumab (Stelara ${ }^{\circledR}$, Janssen Pharmaceuticals) is a fully human monoclonal antibody, which targets the p40 subunit of IL-12 and IL-23. The presumed mechanism of action is to block the binding of IL-12 and IL-23 to receptors on undifferentiated $\mathrm{T}$ cells, preventing differentiation/clonal expansion of pathogenic Th1 and Th17 populations and subsequent downregulation of inflammatory cytokines. ${ }^{85}$

The dosage regimen, precautions and clinical response are summarised in Table XXXI.

\section{General assessment}

Members of the IL-12p40 family, namely IL-12 and IL-23, have been shown to play a pro-inflammatory role in psoriasis. They are produced by activated antigen-presenting cells and have been shown to increase interferon-gamma synthesis by $\mathrm{T}$ cells. IL-23 acts preferentially on interferon gamma production by memory T cells. IL-12 also increases differentiation of naive TH0 to TH1 cells and increases the cytolytic activity of activated T cells and NK cells. ${ }^{86}$

In the European Union, ustekinumab is indicated for the treatment of moderate to severe plaque psoriasis in adults who failed to respond to, have a contraindication to or are intolerant to other systemic therapies, including ciclosporin, methotrexate and PUVA. ${ }^{85}$

In an open-label, phase I study of a single infusion of anti-IL12p40 (ustekinumab), PASI-75 was achieved by $67 \%$ of patients between 8 and 16 weeks after administration of the agent, and in the higher-dose group $100 \%$ of patients achieved PASI-75. ${ }^{87}$ A recent phase III trial (PHOENIX I) of the subcutaneous formulation in patients with moderate to severe psoriasis has demonstrated that $67.1 \%(45 \mathrm{mg})$ and $66.4 \%(90$ $\mathrm{mg}$ ) of patients achieved PASI-75 at week 12. PASI-75 at week 28 was $71.2 \%$ (45 mg) and 78.6\% (90 mg). ${ }^{88}$ Recent evidence from another phase III study (PHOENIX II) in patients with moderate to severe psoriasis demonstrated a maintained treatment response at week 40 , with between $58 \%$ and $67 \%$ of patients achieving PASI-75 at lower $(45 \mathrm{mg})$ and higher $(90 \mathrm{mg})$ dosages, respectively. ${ }^{89}$

Serious adverse events occurred in $4 \%$ of patients who received the monoclonal antibody and in $1 \%$ of those who received placebo. This study demonstrates the therapeutic efficacy of an IL-12/23 monoclonal antibody in psoriasis and provides evidence for a role of IL-12/23 in the pathophysiology of psoriasis. ${ }^{13}$

A recent phase II study in patients with psoriatic arthritis, of whom $85 \%$ had associated skin psoriasis, showed that treatment with ustekinumab (90 mg or $63 \mathrm{mg}$ ) given weekly (weeks 0 - 3) followed by placebo at weeks 12 and 16, demonstrated an ACR 20 response of $42 \%$ for joint disease and a PASI-75 of $52 \%$ for skin disease. In this study ustekinumab treatment reduced the signs and symptoms of arthritis and associated psoriatic skin lesions, as well as significantly improving physical disability and quality of life in the majority of patients. This response was maintained in the majority of patients over week 36, after the last ustekinumab injection at week $3 .{ }^{90}$ No rebound response was reported in this study. ${ }^{90}$

Infections such as tuberculosis are less likely with ustekinumab than with other biologicals, but latent infection should be actively excluded.

\subsubsection{Comparative short-term efficacy of the biologicals}

Two recent meta-analyses have been performed to summarise clinical trial efficacy data enabling a quantitative, indirect comparison between agents, as no current direct 'head-to-head' data between biological agents are available. ${ }^{47,91}$

In the first meta-analysis, 16 randomised, controlled, doubleblind, monotherapy trials of alefacept $(N=3)$, efalizumab $(N=5)$,

\section{Table XXXI. Ustekinumab (no data)}

Recommended dose

\section{Monitoring}

Side-effects

Expected beginning of clinical effect

Clinical response

Level of evidence

Strength of recommendation

Other
The recommended initial dosage of ustekinumab is $45 \mathrm{mg}$ administered subcutaneously at week 0 , followed by a $45 \mathrm{mg}$ dose at week 4 , then every 12 weeks thereafter ${ }^{85}$ For patients with a body weight $>100 \mathrm{~kg}$ the dose is $90 \mathrm{mg}$ administered subcutaneously at week 0 , followed by a $90 \mathrm{mg}$ dose at week 4 , then every 12 weeks thereafter

In patients weighing $>100 \mathrm{~kg}, 45 \mathrm{mg}$ was also shown to be efficacious. However, $90 \mathrm{mg}$ resulted in greater efficacy in these patients ${ }^{85}$

Consideration should be given to discontinuing treatment in patients who have shown no response up to 28 weeks of treatment

Infection screen prior to treatment (NB: active or latent TB must be excluded)

Injection site reactions are common ${ }^{85}$

Response expected by week 4

PASI-75 at 28 weeks achieved by $71.2 \%$ (45 mg)/78.6\% (90 mg); PASI-75 at 40 weeks $58 \%(45 \mathrm{mg})$ and $67 \%(90 \mathrm{mg})^{88}$

Median time to relapse is 15 weeks

No data

No data

Awaiting approval for moderate to severe plaque psoriasis

In development for psoriatic arthritis (phase II completed) 
etanercept $(N=4)$ and infliximab $(N=4)$, comprising 7931 patients, met inclusion criteria. Efficacy was measured by PASI-75 achievement after 10 - 14 weeks of treatment, using intention-to-treat analysis. All biological agents for psoriasis were efficacious $(p<0.001)$; however, there was a graded response for achievement of PASI-75: infliximab (relative risk $(\mathrm{RR})=17.40$, number needed to treat $(\mathrm{NNT})=2)$, etanercept $(R R=11.73, N N T=3)$, efalizumab $(R R=7.34, N N T=4)$ and alefacept $(\mathrm{RR}=3.70, \mathrm{NNT}=8)$. At the same time, the risk of one or more adverse events was evaluated by RR and number needed to harm (NNH). This was increased in the alefacept ( $R R=1.09, p=0.03, \mathrm{NNH}=15)$, efalizumab ( $R R=1.15, p<0.001$, $\mathrm{NNH}=9)$ and infliximab $(\mathrm{RR}=1.18, p<0.001, \mathrm{NNH}=9)$ groups compared with placebo. ${ }^{91}$

In the second meta-analysis 24 RCTs totalling 9384 patients were analysed qualitatively. Sixteen double-blind placebocontrolled trials were eligible for meta-analysis. Efficacy was defined as proportion of participants who had achieved PASI75 at primary efficacy measurement (week 8 - 16). Infliximab was significantly superior to all other interventions (RD 77\%, 95\% CI 72 - 81\%). Adalimumab (RD 64\%, 95\% CI 61 - 68\%) was superior to ciclosporin (RD 33\%, 95\% CI 13 - 52\%), etanercept $50 \mathrm{mg}$ twice weekly (RD 44\%, 95\% CI $40-48 \%$ ) and etanercept $25 \mathrm{mg}$ twice weekly (RD 30\%, 95\% CI 25 - 35\%). ${ }^{47}$

Additionally, a recent poster presentation of a phase III trial (ACCEPT) comparing the efficacy of ustekinumab and etanercept in moderate to severe psoriasis demonstrated that a significantly greater proportion of patients achieved PASI-75 with ustekinumab $45 \mathrm{mg}(67.5 \%, p=0.012)$ and $90 \mathrm{mg}(73.8 \%$, $p<0.001)$ given at weeks 0 and 4 than with etanercept $(56.8 \%)$ given as $50 \mathrm{mg}$ twice weekly. ${ }^{92}$

Ustekinumab has also been compared in a meta-analysis versus the other biological treatments in a recent poster presentation. The estimated mean PASI-75 responses were as follows: infliximab (mean $80 \%, 95 \%$ CI 70 - 87\%), ustekinumab $90 \mathrm{mg}(74 \%$, 68 - 80\%), ustekinumab $45 \mathrm{mg}$ (69\%, 62 - 75\%), adalimumab (58\%, $49-68 \%)$, etanercept $50 \mathrm{mg}$ twice weekly (52\%, 45 - 59\%), etanercept $25 \mathrm{mg}$ twice weekly (39\%, $30-48 \%)$ and supportive care/placebo $(4 \%, 3-4 \%) .{ }^{93}$

\subsubsection{Areas for future research}

The main research gaps remain the great lack of key comparative data and of data concerning the long-term safety and efficacy of biological and non-biological treatments for moderate to severe psoriasis. Additionally, pragmatic headto-head RCTs lasting at least 2 years are needed to compare different biologicals with each other and with conventional systemic treatments for psoriasis. Because biologicals are currently recommended for patients who fail to respond to conventional systemic treatments, the comparative efficacy of biologicals in such a subgroup of treatment failures has to be assessed. $^{63}$

\subsubsection{Choice of agents}

The choice of which of the biological agents to use is based on the clinical pattern of psoriasis, pre-existing co-morbidities, patient preference and local facilities. ${ }^{62}$
A separate recommendation guideline for the use of biologicals in psoriasis is currently underway, and will further clarify the choice of biological agent, based on the most recently available research and clinical data. In the interim readers are requested to refer to the British Association of Dermatologists guidelines or consult the Dermatological Society of South Africa website.

Acknowledgements. The text and tables in this guideline have been modified and adapted with permission from the following international guidelines and sources:

Nast A, Kopp I, Augustin M, Banditt KB, et al. German evidencebased guidelines for the treatment of psoriasis vulgaris (short version). Arch Dermatol Res 2007; 299(3): 111-138. ${ }^{33}$

Smith CH, Anstey AV, Barker JNWN, et al. and Ormerod AD (Chair of the Guideline Group). British Association of Dermatologists guidelines for use of biological interventions in psoriasis 2005. $\mathrm{Br} \mathrm{J}$ Dermatol 2005; 153: 486-497.62

Menter A, Gottlieb A Feldman SR, et al. Guidelines for the care and management of psoriasis and psoriatic arthritis. J Am Acad Dermatol 2008; 58: 826-850..$^{13}$

Winhoven SM, Griffiths CEM. Biologics for psoriasis. May 2005. //www.accessdermatology.com/" www.accessdermatology.com. ${ }^{94}$

Conflict of interest. The authors of these guidelines are all members of the Psoriasis Advisory Board, which received funding from Schering-Plough Pharmaceuticals. Individual members also received honoraria and grants from the company.

The Panel wishes to acknowledge the assistance of Dr Ronell Klingman in the editing of this guideline manuscript.

\footnotetext{
References

1. Ashcroft DM, Li Wan Po A, Griffiths CE. Therapeutic strategies for psoriasis. J Clin Pharm Ther 2000; 25: 1-10.

2. Choi J, Koo JY. Quality of life issues in psoriasis. J Am Acad Dermatol 2003; 49: S57-S61.

3. Brandrup F, Green A. The prevalence of psoriasis in Denmark. Acta Derm Venereol 1981; 61: 344-346.

4. Henseler T, Christophers E. Psoriasis of early and late onset: Characterization of two types of psoriasis vulgaris. J Am Acad Dermatol 1985; 13: 450-456.

5. Elder JT, Nair RP, Guo SW, Henseler T, Christophers E, Voorhees JJ. The genetics of psoriasis. Arch Dermatol 1994; 130(2): 216-224.

6. Whittam LR, McGibbon DH. The management of psoriasis. Int I Clin Pract 1998; 52: 487-491.

7. Asumalahti K, et al. Genetic analysis of PSORS1 distinguishes guttate psoriasis and palmoplantar pustulosis. J Invest Dermatol 2003; 120(4): 627-632.

8. Swanbeck G, et al. Genetic counseling in psoriasis. Empirical data on psoriasis among firstdegree relatives of 3095 psoriatic probands. Br J Dermatol 1997; 137(6): 939-942.

9. Lebwohl M. Psoriasis. Lancet 2003; 361(9364): 1197-1204.

10. Travis L, Weinberg JM. Medical backgrounder: Psoriasis. Drugs Today (Barc) 2002; 38: 847-865.

11. Christophers E. Psoriasis - epidemiology and clinical spectrum. Clin Exp Dermatol 2001; 26: 314-320.

12. Nijsten T, Meads DM, De Korte J, et al. Cross-cultural inequivalence of dermatology-specific health-related quality of life instruments in psoriasis patients. J Invest Dermatol 2007; 127: 2315-2322.

13. Menter A, Gottlieb A, Feldman SR, et al. Guidelines for the care and management of psoriasis and psoriatic arthritis. J Am Acad Dermatol 2008; 58: 826-850.

14. Finlay AY, Khan GK. Dermatology Life Quality Index (DLQI) - a simple practical measure for routine clinical use. Clin Exp Dermatol 1994; 19(3): 210-216.

15. Krueger GG, Feldman SR, Camisa C, et al. Two considerations for patients with psoriasis and their clinicians: what defines mild, moderate, and severe psoriasis? What constitutes a clinically significant improvement when treating psoriasis? J Am Acad Dermatol 2000; 43 281-285.

16. Feldman SR. A quantitative definition of severe psoriasis for use in clinical trials. J Dermatolog Treat 2004; 15: 27-29

17. Lebwohl M, Menter A, Koo J, et al. In: Portland OR, ed. Psoriasis: Treatment Options and Patient Management. Physician Patient Guide. National Psoriasis Foundation, 2002: 30-31. http:// www.psoriasis.org/files/pdfs/press/algorithm.pdf (accessed 12 February 2009).

18. Brandrup F, Green A. The prevalence of psoriasis in Denmark. Acta Derm Venereol 1981; 61: $344-346$

19. Lebwohl M, Christophers E, Langley R, et al. An international, randomized, double-blind, placebo-controlled phase 3 trial of intramuscular alefacept in patients with chronic plaque psoriasis. Arch Dermatol 2003; 139: 719-727.
}

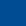


20. Linden KG, Weinstein GD. Psoriasis: current perspectives with an emphasis on treatment. $A m$ J Med 1999; 107: 595-605

21. Koo J, Lebwohl M. Duration of remission of psoriasis therapies. J Am Acad Dermatol 1999; 41 51-59.

22. Lebwohl M, Ali S. Treatment of psoriasis. Part 2. Systemic therapies. J Am Acad Dermatol 2001, 45: 649-661.

23. Compendium of pharmaceuticals and specialties. Ed. Ottawa: Canadian Pharmacists Association, 2004

24. Boerbooms AM, Kerstens PJ, van Loenhout JW, et al. Infections during low-dose methotrexate treatment in rheumatoid arthritis. Semin Arthritis Rheum 1995; 24: 411-421.

25. Lebwohl M, Menter A, Koo J, et al. Combination therapy to treat moderate to severe psoriasis. J Am Acad Dermatol 2004; 50: 416-430.

26. Weinstein GD, White GM. An approach to the treatment of moderate to severe psoriasis with rotational therapy. J Am Acad Dermatol 1993; 28: 454-459.

27. Koo J. Systemic sequential therapy of psoriasis: a new paradigm for improved therapeutic results. I Am Acad Dermatol 1999; 41: S25-S28.

28. van de Kerkhof PC. The management of psoriasis. Neth J Med 1998; 52: 40-45.

29. Krueger G, Koo J, Lebwohl M, et al. The impact of psoriasis on quality of life: results of a 1998 National Psoriasis Foundation patient-membership survey. Arch Dermatol 2001; 137: 280-284.

30. Rapp SR, Feldman SR, Exum ML, et al. Psoriasis causes as much disability as other majo medical diseases. J Am Acad Dermatol 1999; 41: 401-407.

31. Naldi L, Svensson A, Diepgen T, et al. Randomized clinical trials for psoriasis 1977-2000: the EDEN survey. J Invest Dermatol 2003; 120: 738-741.

32. Nast A, Kopp IB, Augustin M, Banditt KB, et al. Deutsche Dermatologische Gesellschaft (DDG); Berufsverband Deutscher Dermatologen (BVDD).Evidence-based (S3) guidelines for the treatment of psoriasis vulgaris. J Dtsch Dermatol Ges 2007; 5 (Suppl 3): 1-119.

33. Nast A, Kopp I, Augustin M, et al. German evidence-based guidelines for the treatment of psoriasis vulgaris (short version). Arch Dermatol Res 2007; 299(3): 111-138.

34. Lebwohl M, Freeman AK, Chapman MS, et al. Tacrolimus ointment is effective for facial and intertriginous psoriasis. J Am Acad Dermatol 2004; 51(5): 723-730.

35. Mentor A, Griffiths CEM. Psoriasis 2. Current and future management of psoriasis. Lancet 2007; 370: $272-284$

36. Griffiths CEM, Clark CM, Chalmers RJ, et al. A systematic review of treatments for severe psoriasis. Health Technol Assess 2000; 4: 1-125.

37. Chalmers RJG. Psoriasis. In: Williams HC, ed. Evidence-based Dermatology. 1st ed. London: Blackwell Publishing, 2003: 226-252.

38. Naldi L, Griffiths CEM. Traditional therapies in the management of moderate to severe chronic plaque psoriasis: an assessment of the benefits and risks. Br I Dermatol 2005; 152 597-615.

39. Yamauchi PS, Rizk D, Lowe NJ. Retinoid therapy for psoriasis. Dermatol Clin 2004; 22: 467476.

40. Marsland AM, Chalmers RJ, Hollis S, et al. Interventions for chronic palmoplantar pustulosis (Review). Cochrane Database Syst Rev 2006, Issue 1. Art. No.: CD001433. DOI: 10.1002/14651858.CD001433.

41. Jones G, Crotty M, Brooks P. Interventions for treating psoriatic arthritis (Review). Cochran Database Syst Rev 2000, Issue 3. Art. No.: CD000212. DOI: 10.1002/14651858.CD000212.

42. Tey HL, Tian EL, Tan AW. Drug interactions in dermatological practice. Clin Expt Dermatol 2008; 33: 541-550.

43. Naldi L, Chalmers RJG. Psoriasis. In: Williams HC, ed. Evidence-based Dermatology. 2nd ed. London: Blackwell Publishing, 2008: 171-188

44. Sandhu K, Kaur I, Kumar B, et al. Efficacy and safety of cyclosporine versus methotrexate in severe psoriasis: a study from north India. I Dermatol 2003; 30: 458-463.

45. Heydendael VMR, Spuls PI, Opmeer BC, et al. Methotrexate versus cyclosporine in moderateto-severe chronic plaque psoriasis. N Engl J Med 2003; 349: 658-665.

46. Flyström I, Stenberg B, Svensson Å et al. Methotrexate vs. ciclosporin in psoriasis: effectiveness, quality of life and safety. A randomized controlled trial. Br J Dermatol 2008; 158 116-121.

47. Schmitt J, Zhang Z, Wozel G, et al. Efficacy and tolerability of biologic and nonbiologic systemic treatments for moderate-to-severe psoriasis: meta-analysis of randomized controlled trials. Br J Dermatol 2008; 159: 513-526.

48. Griffiths CEM, Dubertret L, Ellis CN, et al. Ciclosporin in psoriasis clinical practice: an international consensus statement. Br J Dermatol 2004; 150 (Suppl 67): 11-23.

49. Saurat J-H, Stingl G, Dubertret L, et al. for the CHAMPION Study Investigators. Efficacy and safety results from the randomized controlled comparative study of adalimumab vs. methrotrexate vs. placebo in patients with psoriasis (CHAMPION). Br J Dermatol 2008; 158 $558-566$

50. Ortiz Z, Shea B, Suarez Almazor M, et al. Folic acid and folinic acid for reducing side effects in patients receiving methotrexate for rheumatoid arthritis. Cochrane Database Syst Rev 1999, in patients receiving methotrexate for rheumatoid arthritis. Coch
Issue 3. Art. No.: CD000951. DOI: 10.1002/14651858.CD000951.

51. van Ede AE, Laan RFJM, Rood MJ, et al. Effect of folic or folinic acid supplementation on the toxicity and efficacy of methotrexate in rheumatoid arthritis: a forty-eight week multicentre, randomized, double-blind, placebo-controlled study. Arthritis Rheum 2001; 44: 1515-1524.

52. Salim A, Tan E, Ilchyshyn A, et al. Folic acid supplementation during treatment of psoriasis with methotrexate: a randomized, double-blind, placebo-controlled trial. Br J Dermatol 2006 154: 1169-1174.

53. Chládek J, Simková M, Vanecková J, et al. The effect of folic acid supplementation on the pharmacokinetics and pharmacodynamics of oral methotrexate during the remissioninduction period of treatment for moderate-to-severe plaque psoriasis. Eur J Clin Pharmaco 2008; 64: 347-355.

54. British Association of Dermatologists Guidelines. Psoriasis-general management. http:// www.bad.org.uk/site/769/default.aspx (accessed 18 March 2009).

55. Smith CH. Use of hydroxyurea in psoriasis. Clin Exp Dermatol 1999; 24: 2-6.

6. Lori F, Lisziewicz J. Rationale for the use of hydroxyurea as an anti-human immunodeficiency virus drug. Clin Infect Dis 2000; 30 (Suppl 2): S193-S197.

57. Kumar B, Saraswat A, Kaur I. Rediscovering hydroxyurea: its role in recalcitrant psoriasis. In I Dermatol 2001; 40: 530-534.

58. Lewis V, Finlay AY. Ten years experience of the Dermatology Life Quality Index (DLQI). J Invest Dermatol Symp Proc 2004; 9: 169-180.

59. Ashcroft DM, Li Wan, et al. Clinical measures of disease severity and outcome in psoriasis: a critical appraisal of their quality. Br I Dermatol 1999; 141: 185-191.
60. Finlay AY. Current severe psoriasis and the Rule of Tens. Br J Dermatol 2005; 152: 861-867.

61. Ibbotson $\mathrm{SH}$, Bilsland $\mathrm{D}, \mathrm{Cox} \mathrm{NH}$, et al. An update and guidance on narrowband ultraviole B phototherapy: a British Photodermatology Group Workshop Report. Br I Dermatol 2004; 151: 283-297.

62. Smith $\mathrm{CH}$, Anstey AV, Barker JNWN, et al and Ormerod AD (Chair of the Guideline Group). British Association of Dermatologists guidelines for use of biological interventions in psoriasis 2005. Br J Dermatol 2005; 153: 486-497.

63. Thaçi D. Long-term data in the treatment of psoriasis. Br J Dermatol 2008; 159 (Suppl. 2): 18-24

64. Alefacept package insert. http://www.astellas.us/docs/amevive.pdf (accessed 26 March 2009).

65. Hodak E, David M. Alefacept: a review of the literature and practical guidelines for management. Dermatol Ther 2004; 17: 383-392

66. Cooper KD, Korman NJ. Alefacept in the treatment of psoriasis. Clin Dermatol 2008; 26: 503508.

67. European Medicines Agency recommends suspension of the marketing authorisation of Raptiva (efalizumab). www.emea.europa.eu/humandocs/PDFs/EPAR/raptiva/2085709en. pdf (accessed 26 March 2009).

68. Adalimumab Package Insert. http://www.rxabbott.com/pdf/humira.pdf (accessed 26 March 2009)

69. Menter A, Tyring SK, Gordon K, et al. Adalimumab therapy for moderate to severe psoriasis: A randomised, controlled phase III trial. J Am Acad Dermatol 2008; 58: 106-115.

70. Gordon KB, Langley RG, Leonardi C, et al. Clinical response to adalimumab treatment in patients with moderate to severe psoriasis: Double-blind, randomized controlled trial and open-label extension study. J Am Acad Dermatol 2006; 55: 598-606.

71. Etanercept Package Insert. //www.enbrel.com/pdf/enbrel_pi.pdf" http://www.enbrel. com/pdf/enbrel_pi.pdf (accessed 26 March 2009).

72. Goffe B, Cather JC. Etanercept: An overview. J Am Acad Dermatol 2003; 49 (2 Suppl): S105S111.

73. Gottlieb AB, Matheson, RT, Lowe $\mathrm{N}$, et al. A randomized trial of etanercept as monotherapy for psoriasis. Arch Dermatol 2003; 139: 1627-1632.

74. Paller AS, Sigfried EC, Langley RG, et al. Etanercept treatment for children and adolescents with plaque psoriasis. N Engl J Med 2008; 358: 241-251

75. Mease PJ, Kivitz, AJ, Burch FX, et al. Etanercept treatment of psoriatic arthritis: safety, efficacy and effect on disease progression. Arthritis Rheum 2004, 50: 2264-2272.

76. Lebwohl MG, Gottlieb AB, Walis WI, Zitnik RJ. Global safety and efficacy of more than five years of etanercept (Enbrel) therapy in rheumatoid arthritis. American Academy of Dermatology 62nd Annual Meeting 2004: Washington, DC, poster P550. J Am Acad Dermato 2004 (Suppl 3); 50: 142.

77. Infliximab Package Insert. http://www.remicade.com/remicade/assets/HCP_PPI.pdf (accessed 26 March 2009).

78. Reich K, Nestle FO, Papp K, et al for the EXPRESS study investigators. Infliximab induction and maintenance therapy for moderate-to-severe psoriasis: a phase III, multicentre, doubleblind trial. Lancet 2005; 366: 1367-1374.

79. Data on file. Schering-Plough Pharmaceuticals. http://www.centocororthobiotech.com/ cobi/viewDocumentByTitleAlias.html?title=PR_REMICADE_SONIC_JUNE0209 (accessed 30 June 2009).

80. Winterfield LS. Infliximab. Dermatol Ther 2004; 17: 409-426.

81. Kwon HJ, Cote TR, Cuffe MS, Kramer JM, Braun MM. Case reports of heart failure after therapy with a tumor necrosis factor antagonist. Ann Intern Med 2003; 138: 807-811.

82. Sarzi-Puttini P, Ardizzone S, Manzionna G, et al. Infliximab-induced lupus in Crohn's disease a case report. Dig Liver Dis 2003; 35: 814-817.

83. Baert F, Noman M, Vermeire S, et al. Influence of immunogenicity on the long-term efficacy of infliximab in Crohn's disease. N Engl J Med 2003; 348: 601-608.

84. Robinson WH, Genovese MC, Moreland LW. Demyelinating and neurologic events reported in association with tumor necrosis factor alpha antagonism: by what mechanism could tumo in association with tumor necrosis factor alpha antagonism: by what mechanism could ty
necrosis factor alpha antagonists improve rheumatoid arthritis but exacerbate multiple necrosis factor alpha antagonists improve rhe
sclerosis? Arthritis Rheum 2001; 44: 1977-1983.

85. Ustekinumab EU. Summary of product characteristics. http://www.stelarainfo.com/assets/ pdf/PrescribingInformation.pdf (accessed 15 January 2010).

86. Lee E, Trepicchio WL, Oestreicher JL, et al. Increased expression on interleukin 23 p19 and p40 in lesional skin of patients with psoriasis vulgaris. J Exp Med 2004; 199: 125-130.

87. Kimball AB, Gordon KB, Langley RG, Menter A, Chartash EK, Valdes J for the ABT-874 Psoriasis Study Investigators. Safety and efficacy of abt-874, a fully human interleukin 12/23 monoclonal antibody, in the treatment of moderate to severe chronic plaque psoriasis. Results of a randomized, placebo-controlled, phase 2 trial. Arch Dermatol 2008; 144(2): 200-207.

88. Leonardi CL, Kimball AB, Papp KA, et al. for the PHOENIX 1 study investigators. Efficacy and safety of ustekinumab, a human interleukin-12/23 monoclonal antibody, in patients with psoriasis: 76-week results from a randomised, double-blind, placebo-controlled trial (PHOENIX 1). Lancet 2008; 371: 1665-1674.

89. Papp KA, Langley RG, Lebwohl M, et al. for the PHOENIX 2 Study Investigators. Efficacy and safety of ustekinumab, a human interleukin-12/23 monoclonal antibody, in patients with psoriasis: 52-week results from a randomised, double-blind, placebo-controlled tria (PHOENIX 2). Lancet 2008; 371: 1675-1684

90. Gottlieb A, Menter A, Mendelsohn A, Shen Y-K, Li S, Guzzo C, et al. Ustekinumab, a human interleukin 12/23 monoclonal antibody, for psoriatic arthritis: randomised, double-blind, placebo-controlled, crossover trial. Lancet 2009; 373: 633-640.

91. Brimhall AK, King LN, Licciardone JC, Jacobe H, Menter A. Safety and efficacy of alefacept, etanercept and infliximab in treating moderate to severe plaque psoriasis: a meta-analysis of randomized, controlled trials. Br I Dermatol 2008; 159: 274-285.

92. Griffiths CEM, Strober B, van der Kerkhof PCM, et al. Comparing ustekinumab and etanercept for the treatment of moderate to severe plaque psoriasis. Poster FP1336, presented at EADV (European Academy of Dermatology and Venereology), 17-21 September 2008, Paris.

93. Hawkins N, Huntley A, Eaton J. Meta-analysis of biologic therapies for the treatment of moderate to severe psoriasis. Poster presented at ISPOR (International Society for Pharmacoeconomics and Outcomes Research), 18 May 2009, Orlando, USA.

94. Winhoven SM, Griffiths CEM. Biologics for psoriasis May, 2005. http://www. accessdermatology.com (accessed 26 March 2009).

95. Hernandez C, Cetner AS, Jordan JE, Puangsuvan SN, Robinson JK. Tuberculosis in the age of biologic therapy. I Am Acad Dermatol 2008; 59(3): 363-380. 
